\title{
Moral Hazard versus Liquidity and Optimal Unemployment Insurance
}

\section{Citation}

Chetty, Raj. 2008. Moral hazard versus liquidity and optimal unemployment insurance. Journal of Political Economy 116(2): 173-234.

\section{Published Version}

doi:10.1086/588585

\section{Permanent link}

http://nrs.harvard.edu/urn-3:HUL.InstRepos:9751256

\section{Terms of Use}

This article was downloaded from Harvard University's DASH repository, and is made available under the terms and conditions applicable to Other Posted Material, as set forth at http:// nrs.harvard.edu/urn-3:HUL.InstRepos:dash.current.terms-of-use\#LAA

\section{Share Your Story}

The Harvard community has made this article openly available.

Please share how this access benefits you. Submit a story.

\section{Accessibility}




\title{
Moral Hazard versus Liquidity and Optimal Unemployment Insurance
}

\section{Raj Chetty}

University of California, Berkeley and National Bureau of Economic Research

\begin{abstract}
This paper presents new evidence on why unemployment insurance (UI) benefits affect search behavior and develops a simple method of calculating the welfare gains from UI using this evidence. I show that 60 percent of the increase in unemployment durations caused by UI benefits is due to a "liquidity effect" rather than distortions on marginal incentives to search ("moral hazard") by combining two empirical strategies. First, I find that increases in benefits have much larger effects on durations for liquidity-constrained households. Second, lump-sum severance payments increase durations substantially among constrained households. I derive a formula for the optimal benefit level that depends only on the reduced-form liquidity and moral hazard elasticities. The formula implies that the optimal UI benefit level exceeds 50 percent of the wage. The "exact identification" approach to welfare analysis proposed here yields robust optimal policy results because it does not require structural estimation of primitives.
\end{abstract}

I have benefited from discussions with Joseph Altonji, Alan Auerbach, Olivier Blanchard, Richard Blundell, David Card, Liran Einav, Martin Feldstein, Amy Finkelstein, Jon Gruber, Jerry Hausman, Caroline Hoxby, Juan Jimeno, Kenneth Judd, Lawrence Katz, Patrick Kline, Bruce Meyer, Ariel Pakes, Luigi Pistaferri, Emmanuel Saez, Jesse Shapiro, Robert Shimer, Adam Szeidl, Ivan Werning, anonymous referees, and numerous seminar participants. Philippe Bouzaglou, Greg Bruich, David Lee, Ity Shurtz, Jim Sly, and Philippe Wingender provided excellent research assistance. I am very grateful to Julie Cullen and Jon Gruber for sharing their unemployment benefit calculator and to Suzanne Simonetta and Loryn Lancaster at the Department of Labor for assistance with state unemployment insurance laws. Funding from the National Science Foundation and NBER is gratefully acknowledged.

[ Journal of Political Economy, 2008, vol. 116, no. 2]

(C) 2008 by The University of Chicago. All rights reserved. 0022-3808/2008/11602-0005\$10.00 


\section{Introduction}

One of the classic empirical results in public finance is that social insurance programs such as unemployment insurance (UI) reduce labor supply. For example, Moffitt (1985), Meyer (1990), and others have shown that a 10 percent increase in unemployment benefits raises average unemployment durations by $4-8$ percent in the United States. This finding has traditionally been interpreted as evidence of moral hazard caused by a substitution effect: UI distorts the relative price of leisure and consumption, reducing the marginal incentive to search for a job. For instance, Krueger and Meyer $(2002,2328)$ remark that behavioral responses to UI and other social insurance programs are large because they "lead to short-run variation in wages with mostly a substitution effect." Similarly, Gruber $(2007,395)$ notes that "UI has a significant moral hazard cost in terms of subsidizing unproductive leisure."

This paper questions whether the link between unemployment benefits and durations is purely due to moral hazard. The analysis is motivated by evidence that many unemployed individuals have limited liquidity and exhibit excess sensitivity of consumption to cash on hand (Gruber 1997; Browning and Crossley 2001; Bloemen and Stancanelli 2005). Indeed, nearly half of job losers in the United States report zero liquid wealth at the time of job loss, suggesting that many households may be unable to smooth transitory income shocks relative to permanent income.

Using a job search model with incomplete credit and insurance markets, I show that when an individual cannot smooth consumption perfectly, unemployment benefits affect search intensity through a "liquidity effect" in addition to the moral hazard channel emphasized in earlier work. Intuitively, UI benefits increase cash on hand and consumption while unemployed for an agent who cannot smooth perfectly. Such an agent faces less pressure to find a new job quickly, leading to a longer duration. Hence, unemployment benefits raise durations purely through moral hazard when consumption can be smoothed perfectly, but through both liquidity and moral hazard effects when smoothing is imperfect. ${ }^{1}$

The distinction between liquidity and moral hazard is of interest because the two effects have divergent implications for the welfare consequences of UI. The substitution effect is a socially suboptimal response to the creation of a wedge between private and social marginal costs.

\footnotetext{
${ }^{1}$ I use the term "liquidity effect" to refer to the effect of a wealth grant while unemployed. The liquidity effect differs from the wealth effect (i.e., an increase in permanent income) if the agent cannot smooth consumption perfectly. Indeed, there are models in which the wealth effect is zero but the liquidity effect is positive because of liquidity constraints (see, e.g., Shimer and Werning 2007).
} 
In contrast, the liquidity effect is a socially beneficial response to the correction of the credit and insurance market failures. Building on this logic, I develop a new formula for the optimal unemployment benefit level that depends purely on the liquidity and moral hazard effects. The formula uses revealed preference to calculate the welfare gain from insurance: if an agent chooses a longer duration primarily because he has more cash on hand (as opposed to distorted incentives), we infer that UI benefits bring the agent closer to the social optimum.

The approach to welfare analysis proposed in this paper is very different from the traditional approach of structurally estimating a model's primitives (curvature of utility, borrowing limit, etc.) and then numerically simulating the effects of policy changes. I instead identify a pair of reduced-form elasticities that serve as sufficient statistics for welfare analysis. Conditional on these elasticities, the primitives do not need to be identified because any combination of primitives that matches the elasticities leads to the same welfare results. In this sense, the structural approach is "overidentified" for the purpose of welfare analysis, whereas the method proposed here is "exactly identified." In addition to simplicity, the exact identification approach has two advantages. First, it is less model dependent. While previous studies of unemployment insurance have had to make stark assumptions about borrowing constraints and the lack of private insurance (e.g., Wolpin 1987; Hansen and Imrohoroglu 1992), the formula here requires no such assumptions. Second, it is likely to be more empirically credible. Since one has to identify two parameters rather than a large number of primitives, it is feasible to estimate the relevant elasticities using quasi-experimental variation and relatively few parametric assumptions. ${ }^{2}$

I implement this method empirically by estimating the importance of moral hazard versus liquidity in UI using two complementary strategies. I first estimate the effect of unemployment benefits on durations separately for liquidity-constrained and unconstrained households, exploiting differential changes in benefit levels across states in the United States. Since households' ability to smooth consumption is unobserved, I proxy for it using three measures: asset holdings, single- versus dualearner status, and an indicator for having to make a mortgage payment. I find that a 10 percent increase in UI benefits raises unemployment durations by $7-10$ percent in the constrained groups. In contrast, changes in UI benefits have much smaller effects on durations in the unconstrained groups, indicating that the moral hazard effect is relatively small among these groups. These results suggest that liquidity effects could be quite important in the benefits-duration link. However,

\footnotetext{
${ }^{2}$ The disadvantage of exact identification is that the scope of questions for which it can be used is limited. See Sec. II.E for a detailed comparison of the two approaches.
} 
they do not directly establish that benefits raise the durations of constrained agents by increasing liquidity unless one assumes that the substitution elasticities are similar across constrained and unconstrained groups.

To avoid identification from cross-sectional comparisons between different types of job losers, I pursue a second empirical strategy to estimate the magnitude of the liquidity effect. I exploit variation across job losers in the receipt of lump-sum severance payments, which provide liquidity but have no moral hazard effect. Using a survey of job losers from Mathematica containing information on severance pay, I find that individuals who received severance pay (worth about $\$ 4,000$ on average) have substantially longer durations. An obvious concern is that this finding may reflect correlation rather than causality because severance pay is not randomly assigned. Three pieces of evidence support the causality of severance pay. First, severance payments have a large effect on durations among constrained (low-asset) households but have no effect on durations among unconstrained households. Second, the estimated effect of severance pay is not affected by controls for demographics, income, job tenure, industry, and occupation in a Cox hazard model. Third, individuals who receive larger severance amounts have longer unemployment durations. These findings, though not conclusive given the lack of randomized variation in cash grants, suggest that UI has a substantial liquidity effect.

Combining the point estimates from the two empirical approaches, I find that roughly 60 percent of the marginal effect of UI benefits on durations is due to the liquidity effect. Coupled with the formula derived from the search model, this estimate implies that the marginal welfare gain of increasing the unemployment benefit level from the prevailing rate of 50 percent of the preunemployment wage is small but positive. Hence, the optimal benefit level exceeds 50 percent of the wage in the existing UI system that pays constant benefits for 6 months. An important caveat to this policy conclusion is that it does not consider other types of policy instruments to resolve credit and insurance market failures. A natural alternative tool to resolve credit market failures is the provision of loans. I briefly compare the potential value of loans versus UI benefits using numerical simulations at the end of the paper.

In addition to the empirical literature on unemployment insurance, this paper relates to and builds on several other strands of the literature in macroeconomics and public finance. First, several studies have used consumption data to investigate the importance of liquidity constraints and partial insurance (see, e.g., Zeldes 1989; Johnson, Parker, and Souleles 2006; Blundell, Pistaferri, and Preston 2008). This paper presents analogous evidence from the labor market, showing that labor supply is "excessively sensitive" to transitory income because of imperfections 
in credit and insurance markets. Second, several studies have explored the effects of incomplete insurance and credit markets for job search behavior and UI using simulations of calibrated search models (Hansen and Imrohoroglu 1992; Acemoglu and Shimer 2000). The analysis here can be viewed as the empirical counterpart of such studies, in which the extent to which agents can smooth shocks is estimated empirically rather than simulated from a calibrated model.

The distinction between moral hazard and liquidity effects arises in any private or social insurance program and could be used to calculate the value of insuring other shocks such as health or disability. More generally, it may be possible to develop similar exact identification strategies to characterize the welfare consequences of other government policies beyond social insurance.

The paper proceeds as follows. The search model and formula for optimal benefits are presented in Section II. Section III discusses the evidence on heterogeneous effects of unemployment benefits on durations. Section IV examines the effect of severance payments on durations. The estimates are used to calibrate the formula for welfare gains in Section V. Section VI presents conclusions.

\section{Theory}

I analyze a job search model closely related to the models in Chetty (2003), Lentz and Tranaes (2005), and Card, Chetty, and Weber (2007). The model features (partial) failures in credit and insurance markets, creating a potential role for government intervention via an insurance program. I first distinguish the moral hazard and liquidity effects of UI and then derive a formula for the welfare gain from UI in terms of these elasticities.

\section{A. Agent and Planner's Problems}

Agent's problem.-Consider a discrete-time setting in which the agent lives for $T$ periods, $\{0, \ldots, T-1\}$. Assume that the interest rate and the agent's time discount rate are zero. Suppose that the agent becomes unemployed at $t=0$. An agent who enters a period $t$ without a job first chooses search intensity $s_{t}$. Normalize $s_{t}$ to equal the probability of finding a job in the current period. Let $\psi\left(s_{t}\right)$ denote the cost of search effort, which is strictly increasing and convex. If search is successful, the agent 
begins working immediately in period $t .^{3}$ Assume that all jobs last indefinitely once found.

I make three assumptions to simplify the exposition in the baseline case: (1) the agent earns a fixed pretax wage of $w_{t}$ if employed in period $t$, eliminating reservation wage choices; (2) assets prior to job loss $\left(A_{0}\right)$ are exogenous, eliminating effects of UI benefits on savings behavior prior to job loss; and (3) there is no heterogeneity across agents. These assumptions are relaxed in the extensions analyzed in Section II.D.

If the worker is unemployed in period $t$, he receives an unemployment benefit $b_{t}<w_{t}$. If the worker is employed in period $t$, he pays a tax $\tau$ that is used to finance the unemployment benefit. Let $c_{t}^{e}$ denote the agent's consumption in period $t$ if a job is found in that period. If the agent fails to find a job in period $t$, he sets consumption to $c_{t}^{u}$. The agent then enters period $t+1$ unemployed and the problem repeats.

Let $v\left(c_{t}\right)$ denote flow consumption utility if employed in period $t$ and $u\left(c_{t}\right)$ denote flow consumption utility if unemployed. Assume that $u$ and $v$ are strictly concave. Note that this utility specification permits arbitrary complementarities between consumption and labor.

Search behavior.-The value function for an individual who finds a job at the beginning of period $t$, conditional on beginning the period with assets $A_{t}$, is

$$
V_{t}\left(A_{t}\right)=\max _{A_{t+1} \geq L} v\left(A_{t}-A_{t+1}+w_{t}-\tau\right)+V_{t+1}\left(A_{t+1}\right)
$$

where $L$ is a lower bound on assets. The value function for an individual who fails to find a job at the beginning of period $t$ and remains unemployed is

$$
U_{t}\left(A_{t}\right)=\max _{A_{t+1} \geq L} u\left(A_{t}-A_{t+1}+b_{t}\right)+J_{t+1}\left(A_{t+1}\right)
$$

where

$$
J_{t}\left(A_{t}\right)=\max _{s_{t}} s_{t} V_{t}\left(A_{t}\right)+\left(1-s_{t}\right) U_{t}\left(A_{t}\right)-\psi\left(s_{t}\right)
$$

is the value of entering period $t$ without a job with assets $A_{t}$. It is easy to show that $V_{t}$ is concave because there is no uncertainty following reemployment; however, $U_{t}$ could be convex. In simulations of the model

\footnotetext{
${ }^{3} \mathrm{~A}$ more conventional timing assumption in search models without savings is that search in period $t$ leads to a job that begins in period $t+1$. Assuming that search in period $t$ leads to a job in period $t$ itself simplifies the analytic expressions for $\partial s_{t} / \partial A_{t}$, as shown by Lentz and Tranaes (2005).
} 
with plausible parameters (described below), noncavity never arises. ${ }^{4}$ Therefore, I simply assume that $U_{t}$ is concave in the parameter space of interest.

An unemployed agent chooses $s_{t}$ to maximize expected utility at the beginning of period $t$, given by (3). Optimal search intensity is determined by the first-order condition

$$
\psi^{\prime}\left(s_{t}\right)=V_{t}\left(A_{t}\right)-U_{t}\left(A_{t}\right)
$$

Intuitively, $s_{t}$ is chosen to equate the marginal cost of search effort with its marginal value, which is given by the difference between the optimized values of employment and unemployment.

Planner's problem.-The social planner's objective is to choose the unemployment benefit system that maximizes the agent's expected utility. He could in principle set a different benefit level $b_{t}$ in each period. In this paper, I restrict attention to the "constant benefit, finite duration" class of policies-policies that pay a constant level of benefits $b$ for $B$ periods: $b_{t}=b$ for $t \leq B-1$ and $b_{t}=0$ for $t>B-1$. In practice, most UI benefit policies lie within the constant benefit, finite duration class; for example, $B=26$ weeks in the United States. The problem I analyze here is the optimal choice of $b$, taking the duration of benefits $B$ as exogenously given.

Let $D=\sum_{t=0}^{T-1} \prod_{j=0}^{t}\left(1-s_{j}\right)$ denote the agent's expected unemployment duration and $D_{B}=\sum_{t=0}^{B-1} \prod_{j=0}^{t}\left(1-s_{j}\right)$ denote the agent's expected compensated duration, that is, the expected number of weeks for which he receives unemployment benefits. The planner's problem is to choose the UI benefit level $b$ and tax rate $\tau$ that maximize the agent's expected utility such that expected benefits paid, $D_{B} b$, equal expected taxes collected, $(T-D) \tau$ :

$$
\max _{b, \tau} J_{0}(b, \tau) \quad \text { subject to } D_{B} b=(T-D) \tau \text {. }
$$

I solve this problem in two steps, the first positive and the second normative. I first show that the effect of unemployment benefits can be decomposed into liquidity and moral hazard effects. I then use this decomposition to derive a formula for the optimal benefit level $b^{* .5}$

\footnotetext{
${ }^{4}$ Lentz and Tranaes (2005) also report that nonconcavity never arises in their simulations. They also show that any nonconcavities in $U_{t}$ can be eliminated by introducing a wealth lottery prior to the choice of $s_{t}$.

${ }^{5}$ In the baseline welfare analysis, I take the initial asset level $A_{0}$ as exogenous. I then analyze an extension that allows $A_{0}$ to be endogenously determined by $b$ and also allows for endogenous private insurance.
} 
B. Moral Hazard and Liquidity Effects

To understand the channels through which UI benefits affect search behavior, first consider the effect of a $\$ 1.00$ increase in the benefit level $b_{t}$ on search intensity in period $t$ :

$$
\frac{\partial s_{t}}{\partial b_{t}}=-\frac{u^{\prime}\left(c_{t}^{u}\right)}{\psi^{\prime \prime}\left(s_{t}\right)} .
$$

Next, consider the effects of a $\$ 1.00$ increase in assets $A_{t}$ and a $\$ 1.00$ increase in the period $t$ wage $w_{t}$ :

$$
\frac{\partial s_{t}}{\partial A_{t}}=\frac{v^{\prime}\left(c_{t}^{e}\right)-u^{\prime}\left(c_{t}^{u}\right)}{\psi^{\prime \prime}\left(s_{t}\right)} \leq 0
$$

and

$$
\frac{\partial s_{t}}{\partial w_{t}}=\frac{v^{\prime}\left(c_{t}^{e}\right)}{\psi^{\prime \prime}\left(s_{t}\right)}>0 .
$$

The effect of a cash grant on search intensity depends on the difference in marginal utilities between employed and unemployed states. The reason is that an increase in cash on hand lowers the marginal return to search to the extent that it raises the value of being unemployed relative to being employed. The effect of an increase in $w_{t}$ is proportional to $v^{\prime}\left(c_{t}^{e}\right)$ because a higher wage increases the marginal return to search to the extent that it raises the value of being employed. Combining (6) and (7) yields the decomposition

$$
\frac{\partial s_{t}}{\partial b_{t}}=\frac{\partial s_{t}}{\partial A_{t}}-\frac{\partial s_{t}}{\partial w_{t}} .
$$

Equation (8) shows that an increase in the unemployment benefit level lowers search intensity through two conceptually distinct channels. The first channel is the liquidity effect $\left(\partial s_{t} / \partial A_{t}\right)$ : a higher benefit increases the agent's cash on hand, allowing the agent to maintain a higher level of consumption while unemployed and reducing the pressure to find a new job quickly. The second channel is the moral hazard effect $\left(-\partial s_{t} / \partial w_{t}\right)$ : a higher benefit effectively lowers the agent's net wage $\left(w_{t}-\tau-b_{t}\right)$, reducing the incentive to search though a substitution effect. $^{6}$

\footnotetext{
${ }^{6}$ Technically, $\partial s_{t} / \partial w_{t}$ itself includes an income effect because an increase in the wage rate raises permanent income. Since UI benefits have little impact on total lifetime wealth, this permanent income effect is negligible in this context and $\partial s_{t} / \partial w_{t}$ reflects essentially a pure substitution effect. The decomposition in (8) can therefore be interpreted as a search model analogue of the Slutsky decomposition. The substitution effect reduces the welfare gain from UI, much as a distortionary tax creates a deadweight burden proportional to the substitution effect.
} 
The decomposition above applies to a one-period increase in the UI benefit level. In practice, UI benefit levels are typically changed over multiple weeks simultaneously. For instance, if a benefit of $\$ b$ is paid for the first $B$ weeks of the spell, as in equation (5), an increase in $b$ affects income in the unemployed state in all periods $t \leq B-1$. In this case, the liquidity effect cannot be exactly identified by comparing the effect of a lump-sum cash grant in period 0 to the effect of an increase in $b$ because the timing of receipt of income may matter when agents cannot smooth consumption. Conceptually, this problem can be resolved by introducing an annuity that pays the agent $\$ a_{t}$ regardless of employment status in each period $t=0, \ldots, T-1$. When this annuity is used, it is straightforward to obtain the following generalization of (8), as shown in Appendix A:

$$
\frac{\partial s_{0}}{\partial b}=\left.\frac{\partial s_{0}}{\partial a}\right|_{B}-\left.\frac{\partial s_{0}}{\partial w}\right|_{B}
$$

where the liquidity effect

$$
\left.\frac{\partial s_{0}}{\partial a}\right|_{B}=\sum_{t=0}^{B-1} \frac{\partial s_{0}}{\partial a_{t}}
$$

is the effect of increasing the annuity payment by $\$ 1.00$ in the first $B$ weeks of the spell, and the moral hazard effect

$$
-\left.\frac{\partial s_{0}}{\partial w}\right|_{B}=-\sum_{t=0}^{B-1} \frac{\partial s_{0}}{\partial w_{t}}
$$

is the effect of reducing the wage rate over the first $B$ weeks.

Empirical implications: heterogeneous responses.-The prevailing view in the existing literature is that individuals take longer to find a job when receiving higher UI benefits solely because of the lower private return to work. This pure moral hazard interpretation is valid only for an agent who has access to perfect credit and insurance markets. Since such an agent sets $v^{\prime}\left(c_{0}^{e}\right)=v^{\prime}\left(c_{t}^{e}\right)=u^{\prime}\left(c_{t}^{u}\right)$ for all $t$, the liquidity effect $\left.\left(\partial s_{0} / \partial a\right)\right|_{B}=0$ because an annuity payment raises $V_{t}\left(A_{t}\right)$ and $U_{t}\left(A_{t}\right)$ by the same amount. ${ }^{7}$ At the other extreme, a hand-to-mouth consumer who sets consumption equal to income has $v^{\prime}\left(c_{t}^{e}\right)-u^{\prime}\left(c_{t}^{u}\right)<0$. Since this agent experiences large fluctuations in marginal utility across states, the magnitude of $\left.\left(\partial s_{0} / \partial a\right)\right|_{B}$ can be large for him.

More generally, between the hand-to-mouth and perfect-smoothing

\footnotetext{
${ }^{7}$ Intertemporal smoothing itself cannot completely eliminate fluctuations in marginal utility across the employed and unemployed states because unemployment affects lifetime wealth. Hence, $v^{\prime}\left(c_{t}^{e}\right)$ exactly equals $u^{\prime}\left(c_{t}^{e}\right)$ only if insurance markets are complete.
} 
extremes, individuals who have less ability to smooth will exhibit larger liquidity and total UI benefit effects holding all else constant. To illustrate this heterogeneity, I numerically simulate the search model for agents with different levels of initial assets. I parameterize the search model using constant relative risk aversion utility $(u(c)=v(c)=$ $\left.c^{1-\gamma} /[1-\gamma]\right)$ and a convex disutility of search effort $(\psi(s)=$ $\left.\theta\left[s^{1+\kappa} /(1+\kappa)\right]\right){ }^{8}$ I set $\gamma=1.75, \kappa=0.1, \theta=5$, and $w=\$ 340$ per week. The asset limit is $L=-\$ 1,000$ and $T=500$ (10 years). The UI benefit $b_{t}=b$ is constant for $B=26$ weeks. Finally, assume that the agent receives a baseline annuity payment of $a_{t}=0.25 w=\$ 85$ in each period, which can be interpreted as the income of a secondary earner. At the median initial asset level of $\$ 100$ and weekly UI benefit level of $b=$ $0.5 w=170$, this combination of parameters is roughly consistent with the three key empirical moments used in the welfare calculation in Section V: the average UI-compensated unemployment duration (data: 15.8 weeks; simulation: 15.8 weeks), the ratio of the liquidity effect to the moral hazard effect (data: 1.50; simulation: 1.35 ), and the elasticity of unemployment duration with respect to the benefit level (data: 0.54; simulation: 0.36).

The solid curves in figure 1 plot search intensity in period $0\left(s_{0}\right)$ versus the UI benefit level $b$ for agents with $A_{0}=-\$ 1,000$ and $A_{0}=$ $\$ 13,000$, the twenty-fifth and seventy-fifth percentiles of the initial asset distribution of the job losers observed in the data. As predicted, the effect of UI benefits on search intensity falls with assets: raising the wage replacement rate from $b=0.05 w$ to the actual rate of $b=0.5 w$ reduces search intensity by approximately 55 percent for the low-asset group compared to 22 percent for the high-asset group. The reason for the difference in the benefit effects is that the liquidity effect is much larger for the low-asset agent. To see this, let $a$ denote the increment in the annuity payment when $t \leq 25$, so that $a_{t}=0.25 w+a$ for $t \leq 25$ and $a_{t}=0.25 w$ for $t>25$. The dashed curves in figure 1 plot $s_{0}$ versus $a$, holding the UI benefit $b$ fixed at zero. Increasing the annuity payment from $a=0.05 w$ to $a=0.5 w$ reduces search intensity by 45 percent for the low-asset group, compared to 7 percent for the high-asset group. The liquidity effect thus accounts for the majority of the UI benefit effect for the low-asset agent, whereas moral hazard accounts for the majority of the benefit effect for the high-asset agent.

The liquidity effects are large for agents with low $A_{0}$ because they reduce $c_{t}^{u}$ quite sharply early in the spell, either because of binding borrowing constraints or as a precaution against a protracted spell of joblessness (as in Carroll [1997]). Once agents have a moderate buffer

\footnotetext{
${ }^{8}$ To eliminate degeneracies in the simulation, I cap the probability of finding a job in any given period at 0.25 by assuming $\psi(s)=\infty$ for $s>0.25$.
} 


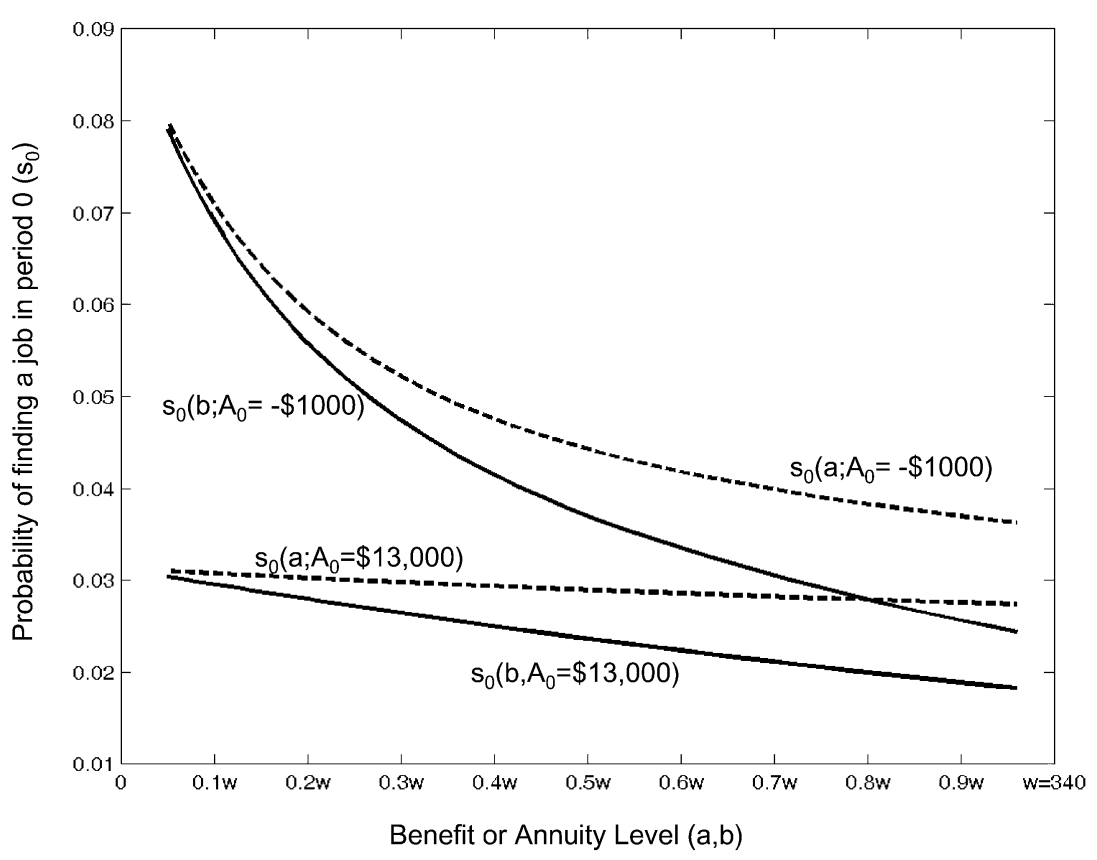

FIG. 1.-UI benefit and liquidity effects by initial assets. This figure plots simulated values of period 0 search intensity $\left(s_{0}\right)$ for two agents, one with $A_{0}=-\$ 1,000$ and the other with $A_{0}=\$ 13,000$. The model is parameterized as follows: utility $u(c)=v(c)=$ $c^{1-\gamma} /(1-\gamma)$ with $\gamma=1.75$; disutility of search $\psi(s)=\theta\left[s^{1+\kappa} /(1+\kappa)\right]$ for $s \leq 0.25$; $\psi(s)=\infty$ for $s>0.25$ with $\kappa=0.1, \theta=5$; wage $w=\$ 340$ per week, asset limit $L=$ $-\$ 1,000, T=500$; UI benefit $b_{t}=b$ for $t \leq 25, b_{t}=0$ for $t>25$; annuity payment $a_{t}=$ $0.25 w+a$ for $t \leq 25$ and $a_{t}=0.25 w$ for $t>25$. Solid curves plot $s_{0}$ as a function of UI benefit level $b$, ranging from $b=0.05 w=\$ 17$ per week to $b=0.95 w=\$ 323$ per week, holding fixed $a=0$. Dashed curves plot $s_{0}$ as a function of an increment in the annuity over the first 26 weeks, holding fixed $b=0$.

stock of assets (e.g., $\left.A_{0}>\$ 10,000\right)$ to smooth temporary income fluctuations, liquidity effects become negligible even though insurance markets are incomplete. Intuitively, intertemporal smoothing is sufficient to make the gap in marginal utilities $v^{\prime}\left(c_{t}^{e}\right)-u^{\prime}\left(c_{t}^{u}\right)$ quite small because unemployment shocks are small on average relative to lifetime wealth. ${ }^{9}$

In this numerical example, the heterogeneity in liquidity effects translates directly into heterogeneity in total responses to UI benefits because the moral hazard effect $\left.\left(\partial s_{0} / \partial w\right)\right|_{B}$ happens to be similar across the two agents. In general, however, $\left.\left(\partial s_{0} / \partial w\right)\right|_{B}$ may not be similar across agents with different asset levels. This motivates a two-pronged approach to

${ }^{9}$ For shocks that have large effects on lifetime wealth (e.g., health, disability), the "liquidity" (non-moral hazard) effect of insurance could be large even for agents who are not liquidity constrained. 
identifying the relative importance of liquidity versus moral hazard effects: (1) estimate how the effect of UI benefits on search behavior varies across liquidity-constrained versus unconstrained individuals and (2) estimate how the effect of annuity payments or lump-sum cash grants on search behavior varies across the same groups. Combining estimates from these two approaches, one can calculate the fraction of the UIduration link due to liquidity versus moral hazard. Before turning to this empirical analysis, I show why this decomposition is of interest from a normative perspective.

\section{Welfare Analysis: Optimal Unemployment Benefits}

Static case.-To simplify the exposition, I begin by characterizing the welfare gain from UI for a static search model $(T=1)$. In this case, the social planner's problem in (5) simplifies to

$$
\begin{aligned}
\max _{b_{0}} \tilde{W}\left(b_{0}\right)= & {\left[1-s_{0}\left(b_{0}\right)\right] u\left(A_{0}+b_{0}\right)+s_{0}\left(b_{0}\right) v\left(A_{0}+w_{0}-\tau\right) } \\
& -\psi\left(s_{0}\left(b_{0}\right)\right)
\end{aligned}
$$

subject to $b_{0}\left[1-s_{0}\left(b_{0}\right)\right]=s_{0}\left(b_{0}\right) \tau$.

The welfare gain from increasing $b_{0}$ by $\$ 1.00$ is

$$
\frac{d \tilde{W}}{d b_{0}}=\left(1-s_{0}\right) u^{\prime}\left(c_{0}^{u}\right)-s_{0} v^{\prime}\left(c_{0}^{e}\right) \frac{d \tau}{d b_{0}} .
$$

Note that

$$
\frac{d \tau}{d b_{0}}=\frac{1-s_{0}}{s_{0}}-\frac{1}{\left(s_{0}\right)^{2}} b_{0} \frac{d s_{0}}{d b_{0}} .
$$

Then it follows that

$$
\frac{d \tilde{W}}{d b_{0}}=\left(1-s_{0}\right)\left[u^{\prime}\left(c_{0}^{u}\right)-v^{\prime}\left(c_{0}^{e}\right)\right]+\frac{d s_{0}}{d b_{0}} \frac{b_{0}}{s_{0}} v^{\prime}\left(c_{0}^{e}\right) .
$$

To obtain a money metric for the welfare gain, I follow Lucas (1987) and define $d W / d b_{0}$ as the ratio of the welfare gain from raising benefits to the welfare gain of increasing the wage rate by $\$ 1.00$. The marginal welfare gain $d W / d b_{0}$ can be expressed as a simple function of the gap in the marginal utilities between the employed and unemployed states:

$$
\frac{d W}{d b_{0}}=\frac{d \tilde{W}}{d b_{0}} \mid s_{0} v^{\prime}\left(c_{0}^{e}\right)=\frac{1-s_{0}}{s_{0}}\left[\frac{u^{\prime}\left(c_{0}^{u}\right)-v^{\prime}\left(c_{0}^{e}\right)}{v^{\prime}\left(c_{0}^{e}\right)}-\frac{\varepsilon_{1-s, b}}{s_{0}}\right],
$$


where

$$
\varepsilon_{1-s, b}=\frac{b_{0}}{1-s_{0}} \frac{d\left(1-s_{0}\right)}{d b_{0}}
$$

is the elasticity of the probability of being unemployed with respect to the benefit level. From equations (6) and (7), (10) can be rewritten as

$$
\frac{d W}{d b_{0}}=\frac{1-s_{0}}{s_{0}}\left(\frac{-\partial s_{0} / \partial A_{0}}{\partial s_{0} / \partial w_{0}}-\frac{\varepsilon_{1-s, b}}{s_{0}}\right) .
$$

This formula shows that the welfare gain from increasing $b$ can be calculated purely using estimates of the liquidity and moral hazard effects. Since all the inputs in (11) are endogenous to $b_{0}$, the value of $d W / d b_{0}$ applies only locally. Given concavity of $W\left(b_{0}\right), b_{0}^{*}$ satisfies $d W\left(b_{0}^{*}\right) / d b_{0}=0$. Hence, (11) provides a test for whether the benefit level at which the elasticities are estimated is optimal. The sign of $d W / d b_{0}$ indicates whether the optimal benefit level is above or below the current level.

An interesting implication of (11) is that an analyst who assumes away liquidity effects can immediately conclude that UI strictly reduces welfare $\left(\partial s_{0} / \partial A_{0}=0 \Rightarrow d W / d b_{0}<0\right)$, because he has effectively assumed that markets are complete. The optimal UI problem warrants analysis only when there are liquidity effects. I provide intuition for this result and the formula in (11) after generalizing it to $T>1$.

Dynamic case.-Now consider the general problem in (5), where UI benefits are paid at a constant level $b$ for $B \leq T$ periods. As above, one can construct a money metric for the welfare gain from UI by comparing the effect of a $\$ 1.00$ increase in $b$ with a $\$ 1.00$ increase in the wage rate $w$ on the agent's expected utility:

$$
\frac{d W}{d b} \equiv \frac{d J_{0}}{d b} \mid \sum_{t=0}^{T-1} \frac{d J_{0}}{d w_{t}} .
$$

Let $\sigma=(T-D) / T$ denote the fraction of his life the agent is employed. Let $\varepsilon_{D_{B}, b}=\left(b / D_{B}\right)\left(d D_{B} / d b\right)$ and $\varepsilon_{D, b}=(b / D)(d D / d b)$ denote the total elasticities of the UI-compensated and total unemployment duration with respect to the UI benefit level, taking into account the effect of the increase in $\tau$ needed to finance the increase in $b$.

When $T>1$, the effects of benefit and tax increases on welfare depend on the entire path of marginal utilities after reemployment. In addition, when $B<T, d W / d b$ depends on both $D_{B}$ and $D$. These factors make the formula for $d W / d b$ more complex, as shown in the following proposition.

Proposition 1. Suppose that UI benefits are paid for $B$ periods at 
a level $b$. The welfare gain from raising $b$ by $\$ 1.00$ relative to a $\$ 1.00$ increase in the wage is

$$
\frac{d W}{d b}(b)=\frac{1-\sigma}{\sigma} \frac{D_{B}}{D}\left\{(1-\rho) \frac{-\left.\left(\partial s_{0} / \partial a\right)\right|_{B}}{\left.\left(\partial s_{0} / \partial w\right)\right|_{B}}-\rho-\frac{1}{\sigma}\left[(1-\sigma) \varepsilon_{D, b}+\sigma \varepsilon_{D_{B}, b}\right]\right\},
$$

where

$$
\rho=\frac{E_{0, B-1} v^{\prime}\left(c_{t}^{e}\right)-v^{\prime}\left(c_{0}^{e}\right)}{E_{0, T-1} v^{\prime}\left(c_{t}^{e}\right)} \frac{B}{D_{B}}+\frac{E_{0, B-1} v^{\prime}\left(c_{t}^{e}\right)-E_{0, T-1} v^{\prime}\left(c_{t}^{e}\right)}{E_{0, T-1} v^{\prime}\left(c_{t}^{e}\right)},
$$

and $E_{0, s} v^{\prime}\left(c_{t}^{e}\right)$ denotes the average marginal utility of consumption after reemployment conditional on finding a job before period $s$.

Proof. The general logic of the proof is to write the welfare gain in terms of marginal utilities, as in (10), and then relate these marginal utilities to the moral hazard and liquidity comparative statics. See Appendix A for details.

The formula for $d W / d b$ when $T \geq B>1$ differs from the formula in (11) for the static case in three respects. First, the welfare gain depends on a new parameter $\rho$ in addition to the liquidity and moral hazard effects. The parameter $\rho$ is an increasing function of the sensitivity of consumption upon reemployment to the length of the preceding unemployment spell, that is, the rate at which $v^{\prime}\left(c_{t}^{e}\right)$ rises with $t$. The $\rho$ term enters the formula because part of the liquidity effect arises from the difference in expected marginal utilities after reemployment at different dates when $T>1$. This component of the liquidity effect has to be subtracted out, because only the difference in marginal utilities between the employed and unemployed states matters for optimal UI.

Second, when $B<T, d W / d b$ depends on a weighted average of $\varepsilon_{D, b}$ and $\varepsilon_{D_{R}, b}$ because $d \tau / d b$ is determined by both the time the agent spends in the UI system and the time he spends working and paying taxes. Third, the welfare gain is scaled down by $D_{B} / D<1$ because UI benefits are paid for only a fraction $D_{B} / D$ of the unemployment spell, reducing the welfare gain from raising $b$ relative to the welfare gain of a permanent wage increase.

Approximate formula.-There are two complications in connecting the empirical estimates below to the inputs called for in (12). First, the empirical analysis does not yield an estimate of $\rho$. Second, the liquidity effect $\left.\left(\partial s_{0} / \partial a\right)\right|_{B}$ depends on the effect of a $\$ 1.00$ increase in an annuity payment, but the only variation in the data is in lump-sum severance payments-that is, variation in $A_{0}$.

To address the first issue, I use the approximation that the consumption path upon reemployment is flat, that is, that $c_{t}^{e}$ does not vary 
with $t$. This is an intuitive assumption because consumption reverts to the present value of lifetime wealth upon reemployment, and unemployment spells typically have negligible effects on subsequent lifetime wealth. The flat consumption path approximation implies $\rho=0$.

To calculate the liquidity effect, I translate the effect of a lump-sum grant, $\partial s_{0} / \partial A_{0}$, into the effect of a $B$-period annuity, $\left.\left(\partial s_{0} / \partial a\right)\right|_{B}$. When the maximum duration of benefits $B$ is relatively short, as in the United States, it is plausible to assume that the borrowing constraint is slack in weeks 0 to $B-1$. The reason is that the agent maintains a buffer stock in case his spell extends beyond the $B$ weeks (as verified by the simulations below). Hence, a $\$ 1.00$ annuity payment over the first $B$ weeks is equivalent to a $\$ B$ cash grant in period 0 , since the Euler equation holds and the agent can exchange money freely across weeks. Even if the borrowing constraint does bind at some point before week $B$, the short length of most spells suggests that a $\$ 1.00$ annuity payment will be approximately equal to a $\$ B$ grant:

$$
\left.\frac{\partial s_{0}}{\partial a}\right|_{B} \approx B \frac{\partial s_{0}}{\partial A_{0}} .
$$

To further simplify the formula, I assume that $\varepsilon_{D, b}=\varepsilon_{D_{B}, b^{\circ}}{ }^{10}$ With these approximations, it follows immediately that (12) reduces to a simple function of the effects of lump-sum grants and benefit increases on search intensity at the beginning of the spell.

Corollary 1. Under the approximations that (i) $c_{t}^{e}$ does not vary with $t$, (ii) $\varepsilon_{D, b}=\varepsilon_{D_{B}, b}$, and (iii) the borrowing constraint is slack before period $B$, the welfare gain from raising $b$ is

$$
\frac{d W}{d b}=\frac{1-\sigma}{\sigma} \frac{D_{B}}{D}\left(R-\frac{\varepsilon_{D_{B},}}{\sigma}\right),
$$

where the liquidity to moral hazard ratio

$$
R \equiv \frac{-\left.\frac{\partial s_{0}}{\partial a}\right|_{B}}{\left.\frac{\partial s_{0}}{\partial a}\right|_{B}-\frac{\partial s_{0}}{\partial b}}=\frac{-B \frac{\partial s_{0}}{\partial A_{0}}}{B \frac{\partial s_{0}}{\partial A_{0}}-\frac{\partial s_{0}}{\partial b}} .
$$

Quality of approximations.-How accurate of an approximation does (14) provide for the actual welfare gain? I answer this question by com-

\footnotetext{
${ }^{10}$ This approximation is supported empirically: the elasticity estimates in Sec. IV, which measure "duration" as time between jobs, are similar to those in studies that measure duration as time in the UI system (e.g., Meyer 1990).
} 


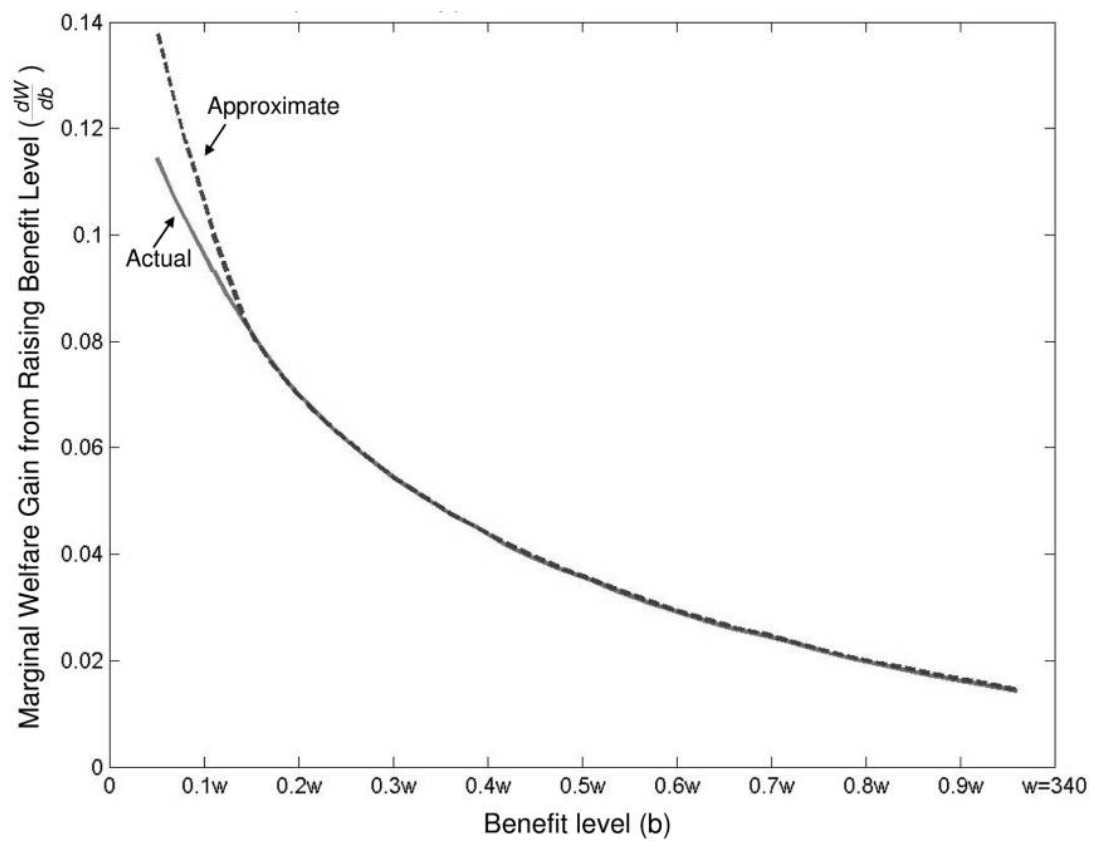

Fig. 2.-Comparison of approximate and actual welfare measures. This figure plots the marginal welfare gain of raising the UI benefit level, defined as the change in the agent's expected utility from raising $b$ divided by the change in expected utility from raising the wage by $\$ 1.00$ in all periods. The solid curve shows the actual (numerically simulated) value of $d W / d b$ as a function of $b$. The dashed curve shows the approximate value calculated using the formula in corollary 1 . The simulation assumes $A_{0}=\$ 100$ and all other parameters as in fig. 1.

paring the actual (numerically calculated) and approximate welfare gains from raising the benefit level using simulations with the same parameterization as in Section II. $B$ and $A_{0}=100$. I compute the actual welfare gain by calculating $J_{0}(b, w)$ numerically and defining

$$
\frac{\partial W}{\partial b}=\frac{J_{0}(b+1)-J_{0}(b)}{J_{0}(w+1)-J_{0}(w)} .
$$

I compute the approximate welfare gain by calculating $\partial s_{0} / \partial A_{0}$, $\partial s_{0} / \partial b$, and $\varepsilon_{D_{B}, b}$ numerically and applying the formula in corollary 1 .

Figure 2 plots the actual and approximate values of $d W / d b$ as a function of the wage replacement rate $b / w$. The figure shows, for instance, that the welfare gain of raising the UI benefit level by $\$ 1.00$ starting from a replacement rate of 50 percent is equivalent to a permanent 3.5 cent wage increase. The welfare gain falls with $b$ because $J_{0}$ is concave in $b$ : there are diminishing returns to correcting market failures. The approximate welfare gain is very similar to the actual welfare gain, with 
an average deviation of 0.2 cent over the range plotted. At all but the lowest replacement rates $(b / w<15$ percent $)$, the approximate and actual measures are indistinguishable. The similarity is striking given how much less information is used to implement the approximate formula than the actual ("structural approach") measure.

The approximation works well for two reasons. First, the consumption path upon reemployment $\left\{c_{t}^{e}\right\}$ is quite flat; for example, when $b=$ $0.5 w, c_{0}^{e}=\$ 423.50$ and $c_{26}^{e}=\$ 423.46$. As a result, $\rho$ is close to zero $(\rho=-0.002){ }^{11}$ Second, the borrowing constraint is slack for $t<26$ when $b / w>15$ percent. Since benefits are provided for only 26 weeks, the agent retains a buffer stock to insure against the risk of a spell beyond 26 weeks. For instance, when $b=0.5$, the agent enters week 26 with $\$ 75$ in assets if he is still unemployed at that time, even though he could have borrowed up to $\$ 1,000$. The annuity to cash grant conversion in (13) therefore holds exactly for $b>0.15 w$. When $b<0.15 w$, the borrowing constraint starts to bind in the fourth or fifth month, leading to a modest error in the annuity conversion because most spells end before this point. ${ }^{12}$

The welfare gain remains positive even at $b=0.95 \mathrm{w}$ because of the stylized nature of the simulation. Allowing for private-market or informal insurance mechanisms would substantially reduce the simulated welfare gains, particularly at high benefit levels. This sensitivity to modeling assumptions is precisely the advantage of using the elasticity-based formula in (14) rather than simulating the welfare gains from the structural model, as I discuss below.

\section{Extensions}

Endogenous ex ante behavior.-The preceding welfare analysis assumed that behavior prior to job loss is invariant to the unemployment benefit level. In practice, higher benefits might reduce precautionary saving and private market insurance arrangements. To understand how such ex ante behavioral responses affect corollary 1 , suppose that the agent is employed at wage $w_{-1}-\tau$ in period $t=-1$. He faces a (fixed) probability $p$ of being laid off in period 0 , at which point the problem specified in Section II. $A$ begins. With probability $1-p$, the agent is granted tenure and remains employed until $T$. The agent can purchase an in-

\footnotetext{
${ }^{11}$ In this numerical example, $\left\{c_{t}^{e}\right\}$ is particularly flat because the agent does not borrow against future earnings while unemployed prior to week $B=26$ because of the risk that the spell may extend beyond the UI exhaustion date. In the working paper version (Chetty 2008), I give a bounding argument showing that $\rho<0.015$ irrespective of the agent's borrowing decisions.

${ }^{12}$ If $\left.\left(\partial s_{0} / \partial a\right)\right|_{B}$ were empirically estimable, the approximate measure would remain equally accurate for $b / w<15$ percent. Hence, the only potentially nontrivial source of approximation error is the annuity conversion in (13).
} 
surance policy that pays $\$ z$ if he is laid off and charges a premium $\omega(z)$ if he remains employed. ${ }^{13}$ The agent's value function in period -1 is

$$
\begin{aligned}
J_{-1}\left(A_{-1}\right)= & \max _{A_{0}, z} v\left(w_{-1}-\tau-A_{0}\right)+p J_{0}\left(A_{0}+z\right) \\
& +(1-p) T v\left(w_{t}-\tau+\frac{A_{0}-\omega(z)}{T}\right) .
\end{aligned}
$$

The social planner's problem is to

$$
\max _{b, \tau} J_{-1}(b, \tau) \quad \text { subject to } p D_{B} b=(T+1-p D) \tau .
$$

Let us redefine

$$
\frac{d W}{d b} \equiv \frac{d J_{-1}}{d b} \mid \sum_{t=-1}^{T-1} \frac{d J_{-1}}{d w_{t}}
$$

and the fraction of time employed as $\sigma=(T+1-p D) /(T+1)$. In Appendix A, I show that corollary 1 remains valid in this extended model subject to one caveat: the derivatives $\left.\left(\partial s_{0} / \partial a\right)\right|_{B}$ and $\partial s_{0} / \partial b$ must be evaluated holding the ex ante choices of $A_{0}$ and $z$ fixed. ${ }^{14}$ Intuitively, endogenous ex ante behaviors have no effect on the marginal utility representation in (10) because of envelope conditions that eliminate first-order effects of these behavioral responses. The liquidity and moral hazard comparative statics, however, are confounded by changes in ex ante behavior, breaking the link between the ratio $R$ and the gap in marginal utilities between the employed and unemployed states. Conditioning on $A_{0}$ and $z$ when calculating the derivatives restores the link between $\left.\left(\partial s_{0} / \partial a\right)\right|_{B} /\left(\partial s_{0} / \partial b\right)$ and the gap in marginal utilities.

Thus, (14) holds with endogenous ex ante behavior, but the variation used to estimate the liquidity and moral hazard effects must be chosen judiciously. In the empirical application below, $\partial s_{0} / \partial b$ is estimated from unanticipated changes in benefit rules, making it plausible that ex ante behaviors are unaffected by the variation in $b$. In other contexts, such as cross-sectional comparisons of unemployment durations across states or countries, ex ante behavioral responses may affect the elasticities.

\footnotetext{
${ }^{13}$ There is still a potential role for government-provided insurance in this model because private insurance may have a load, $\omega(z)>[p /(1-p)] z$. Note that the private insurance policy considered here does not induce moral hazard because it does not affect the marginal incentive to search. Allowing for private insurance policies that induce moral hazard requires a modification of the formula because of a fiscal externality problem. See Chetty and Saez (2008) for an extension of the formula in (14) to this case.

${ }^{14}$ If $\left.\left(\partial s_{0} / \partial a\right)\right|_{B}$ is estimated using the variation in severance payments and the annuity conversion in (13), the effect of severance pay on durations must be estimated holding fixed savings behavior prior to job loss.
} 
Stochastic wage offers.-How does allowing for uncertainty in the wage offer affect the formula for $d W / d b$ ? Consider a model in which search intensity $s_{t}$ controls the arrival rate of wage offers, which are drawn from a distribution $F(w)$. In this environment, the agent chooses both $s_{t}$ and a reservation wage $R_{t}$ below which he rejects job offers (McCall 1970). The formula in corollary 1 still applies in this environment (see App. A). The logic for why the result generalizes can be seen in three steps. First, the envelope conditions used to write $d W / d b$ in terms of expected marginal utilities still hold because $R_{t}$ is simply another optimized variable. Second, the first-order condition for search intensity in (4) applies irrespective of the wage distribution, allowing us to relate the expected marginal utilities to the comparative statics of search intensity as above. Finally, using the approximation that the mean level of consumption upon reemployment is flat over time (analogous to the $\rho=0$ approximation above), one obtains (14).

Although the formula for $d W / d b$ has the same form, more information is required to implement it empirically when wage offers are stochastic. Changes in empirically observed job-finding hazards cannot be directly used to infer the relevant changes in search intensity $\left(\partial s_{0} / \partial a, \partial s_{0} / \partial b\right)$ because part of the change in job-finding hazards comes from changes in the reservation wage. In Appendix A, I show that (14) can be implemented when wages are stochastic using data on mean accepted wages. The change in the mean accepted wage can be used to infer how much of a change in job-finding rates is due to changes in search intensity versus the reservation wage. Intuitively, the effect of UI benefits on the reservation wage will be manifested in changes in ex post accepted wages. Recent evidence indicates that UI benefit levels have little effect on wages and other measures of the accepted job's quality (Card et al. 2007; van Ours and Vodopivec 2008). In light of this evidence, the empirical implementation of (14) in Section V-in which changes in hazard rates are equated with changes in $s_{t}$-is valid even with stochastic wage offers. ${ }^{15}$

Heterogeneity.-The empirical analysis below reveals considerable heterogeneity in liquidity and UI benefit effects. How does such heterogeneity affect the calculation of $d W / d b$ if the government sets a single benefit level as above? Consider a model in which agents have heterogeneous preferences and asset levels and the government has a utili-

\footnotetext{
${ }^{15}$ Aside from its implications for the link between search intensity and hazard rates, the evidence on match quality effects has no bearing on the optimal benefit level under the revealed-preference test proposed here. It does not matter if the agent chooses to use the money to consume more leisure or search for a better match. Conditional on $\partial s_{0} / \partial a$ and $\partial s_{0} / \partial b$, evidence on search outcomes matters for welfare analysis only if the preferences revealed by choice are not those that the social planner wishes to maximize (e.g., because of time inconsistency).
} 
tarian social welfare function. Define $d W / d b$ as the aggregate marginal welfare gain from raising $b$ relative to raising the wage rate for all agents. Then $d W / d b$ has the same representation as in (10), replacing the marginal utilities by average marginal utilities across agents (see App. A). However, connecting the gap in average marginal utilities to the ratio of the mean liquidity and moral hazard effects

$$
\bar{R}=\frac{-B \times E\left(\partial s_{0} / \partial A\right)}{E\left(\partial s_{0} / \partial b\right)}
$$

requires additional assumptions. The reason is that agents with high values of $\psi^{\prime \prime}\left(s_{0}\right)$ receive less weight in both the mean liquidity and moral hazard effects since their behavior is less elastic to policy changes. But all agents receive equal weight in the welfare calculation under the utilitarian criterion. If the heterogeneity in marginal utilities $\left(v^{\prime}\left(c_{t}^{e}\right)\right.$, $\left.u^{\prime}\left(c_{t}^{e}\right)\right)$ is orthogonal to the heterogeneity in $\psi^{\prime \prime}\left(s_{0}\right)$ - that is, if the parameters that control heterogeneity in preferences over consumption and disutility of search are independently distributed-the $\psi^{\prime \prime}\left(s_{0}\right)$ terms cancel out of $\bar{R}$. Under this independence assumption, the formula for $d W / d b$ in corollary 1 measures the mean per capita welfare gain of raising $b$ when calibrated using mean effects as in Section V.

\section{E. Discussion}

Intuition for the test.-The analysis above has shown that the optimal benefit level does not necessarily fall with $\varepsilon_{D, b}$, contrary to conventional wisdom. It matters whether a higher value of $\varepsilon_{D, b}$ comes from a larger liquidity, $-\left.\left(\partial s_{0} / \partial a\right)\right|_{B}$, or moral hazard, $\left.\left(\partial s_{0} / \partial w\right)\right|_{B}$, component. To the extent that it is the liquidity effect, UI reduces the need for agents to rush back to work because they have insufficient ability to smooth consumption; if it is primarily the moral hazard effect, UI is subsidizing unproductive leisure. In this sense, the formula for optimal UI proposed here can be interpreted as a new method of quantifying the extent to which the full insurance benchmark is violated. The agent's capacity to smooth marginal utilities is assessed by examining the effect of transitory income shocks on the consumption of leisure instead of goods as in earlier studies (Cochrane 1991; Gruber 1997).

More generally, the concept underlying (14) is to measure the value of insurance using revealed preference. The effect of a lump-sum cash grant on the unemployment duration reveals the extent to which the UI benefit permits the agent to attain a more socially desirable allocation. If a lump-sum grant has no effect on the duration of search, we infer that the agent is taking more time to find a job when the UI benefit level is increased purely because of the price subsidy for doing 
so. In this case, UI simply creates inefficiency by taxing work, and $d W / d b<0$. In contrast, if the agent raises his duration substantially even when he receives a nondistortionary cash grant, we infer that the UI benefit permits him to make a more (socially) optimal choice, that is, the choice he would make if the credit and insurance market failures could be alleviated without distorting incentives. The test thus identifies the policy that is best from the libertarian criterion of correcting market failures as revealed by individual choice.

Comparison to alternative methods. - The most widely used existing method of policy analysis is the structural approach, which involves two steps. First, estimate the primitives using a parameterized model of behavior-for example, the curvature of the utility function, the cost of search effort, or the borrowing limit. Second, simulate the effect of policy changes using the estimated model, as in the calculation of the actual welfare gain in figure 2. Wolpin (1987) pioneered the application of this approach to job search; more recent examples include Hansen and Imrohoroglu (1992), Hopenhayn and Nicolini (1997), and Lentz (2008).

In contrast with the structural approach, the formula in corollary 1 leaves the primitives unidentified. It instead identifies a set of high-level moments $\left(\varepsilon_{D_{B}, b}, R\right.$, and $\left.D_{B}\right)$ that are sufficient statistics for the marginal value of insurance (up to the approximations necessitated by data limitations). The primitives do not need to be identified because any combination of primitives that matches $\left(\varepsilon_{D_{B},}, R\right.$, and $\left.D_{B}\right)$ at a given level of $b$ implies the same value of $d W(b) / d b$. For example, any primitives consistent with these three moments at $b=0.5 w$ in figure 2 would lead to $d W(b=0.5 w) / d b=0.035$. Changes in the primitives affect the marginal welfare gain only through these three moments because of envelope conditions that arise from agent optimization (see also Chetty 2006a). Thus, the three moments exactly identify the welfare gain from UI.

The same concept of exact identification underlies the consumptionbased formula for optimal UI benefits of Baily (1978) and Chetty (2006a) and the reservation wage formula of Shimer and Werning (2007). Each of these papers identifies a different sufficient statistic for welfare analysis. One advantage of the moral hazard versus liquidity method is that it requires data only on unemployment durations, which are typically more precise and widely available than data on consumption or reservation wages. In addition, this method does not rely on consumption-labor separability $(u=v)$ or a specific parameterization of the utility function and can be easily implemented when benefits have finite duration $(B<T) .{ }^{16}$

\footnotetext{
${ }^{16}$ The formula here does, however, assume separability of utility over consumption and search effort in the unemployed state. Complementarities between $c_{t}$ and $s_{t}$ can be handled by estimating the cross-partial using the technique in Chetty $(2006 b)$.
} 
The general advantage of exact identification methods relative to the structural approach is that they require much less information about preferences and technology. For instance, (14) is invariant to assumptions about market completeness, as measured by the asset limit $L$ and the cost of private insurance $\omega(z)$. Structural approaches, in contrast, often require assumptions such as no intertemporal smoothing or no private insurance to operationalize the analysis. Moreover, even granted such assumptions, it is challenging to identify every primitive consistently in view of model misspecification and omitted variable concerns. A biased estimate of any one of the structural primitives creates bias in the welfare analysis. Since it is easier to estimate a small set of elasticities using credible identification strategies, exact identification is likely to yield more empirically and theoretically robust welfare conclusions.

The disadvantage of (existing) exact identification strategies is the limited scope of questions that they can answer. One cannot, for example, make statements about the welfare gain from an indefinite $(B=T)$ UI benefit using the method developed above when the variation in the data is only in finite duration $(B<T)$ policies. In addition, because the elasticity inputs to the formula are endogenous to the policy itself, exact identification can be used only to calculate marginal welfare effects-that is, the effect of local changes in policy around observed values. Structural methods, in contrast, can in principle be used to simulate the welfare effect of any policy change once the primitives have been estimated, since the primitives are by definition exogenous to policy changes. ${ }^{17}$

In the remainder of the paper, I calculate the welfare gain from raising the UI benefit level in the United States by estimating $\partial s_{0} / \partial b$ and $\partial s_{0} / \partial A_{0}$. I compare the results of this method with results of other approaches in the existing literature in Section V.

\section{Empirical Analysis I: The Role of Constraints}

\section{A. Estimation Strategy}

The objective of the empirical analysis is to estimate the liquidity and total benefit effects for liquidity-constrained and unconstrained households. The empirical strategy follows from the positive analysis in Section II. $B$; I essentially estimate the slope of the four curves simulated in figure 1. I begin by comparing the effect of UI benefits on durations for unconstrained and constrained individuals. This comparison gives an

\footnotetext{
${ }^{17}$ In practice, structural estimation generally relies on out-of-sample parametric extrapolations to make statements about policies outside the region observed in the data. Using such extrapolations, one could potentially extend the exact identification welfare results outside the observed region as well.
} 
indication of the importance of liquidity relative to moral hazard. For instance, if the effects of benefits on durations were much stronger in the unconstrained group, it would be unlikely that liquidity effects are large.

To implement this heterogeneity analysis, I divide individuals into unconstrained and constrained groups and estimate benefit duration elasticities for each group using cross-state and time variation in unemployment benefit levels. The ideal definition of the unconstrained group would be the set of households whose marginal utility is not sensitive to transitory income shocks, that is, those that have $\Delta=$ $u^{\prime}\left(c_{t}^{u}\right)-v^{\prime}\left(c_{t}^{e}\right) \simeq 0$. Unfortunately, there is no panel data set that contains high-frequency information on both household consumption and labor supply in the United States. I therefore use proxies to identify households that can smooth consumption intertemporally, which should have $\Delta \simeq 0$ as shown in the simulations above. ${ }^{18}$

The primary proxy I use is liquid wealth net of unsecured debt at the time of job loss, which I term "net wealth." Browning and Crossley (2001), Bloemen and Stancanelli (2005), and Sullivan (forthcoming) report evidence from various panel data sets showing that households with little or no financial assets prior to job loss suffer consumption drops during unemployment that are mitigated by provision of UI benefits. In contrast, households with higher assets exhibit little sensitivity of consumption to unemployment or UI benefit levels. ${ }^{19}$

I also consider two secondary proxies: spousal work status and mortgage status prior to job loss. Browning and Crossley find larger consumption drops and higher sensitivity to UI among single-earner households. Their interpretation of this finding is that those with a second income source are more likely to be able to borrow since at least one person is employed..$^{20}$ The mortgage proxy is motivated by Gruber's (1998) finding that fewer than 5 percent of the unemployed sell their homes during a spell, whereas renters move much more frequently. Consequently, an individual making mortgage payments before job loss effectively has less ability to smooth the remainder of his consumption (Chetty and Szeidl 2007) and is more likely to be constrained than a renter.

\footnotetext{
${ }^{18}$ An alternative strategy, which I do not pursue here because of data limitations, is to distinguish households by their ability to smooth consumption across states through risksharing mechanisms.

${ }^{19}$ Related evidence is given by Blundell et al. (2008), who find that consumption-income comovement is much larger for low-asset households.

${ }^{20}$ A countervailing effect is that households with a single earner may be able to maintain their prior standard of living more easily if the other earner can enter the labor force to make up for the lost income. Browning and Crossley's findings suggest that this effect is dominated by the added intertemporal smoothing capacity of dual earners, so that on net households with two earners are less constrained.
} 
Although these proxies predict being constrained on average, they are imperfect predictors for two reasons. First, some households classified as unconstrained are presumably misallocated to the constrained group and vice versa. Second, no household truly has $\Delta=0$ because insurance markets are likely to be incomplete. There is therefore a small liquidity effect even among the groups classified as unconstrained, as shown in figure 1. Since I attribute the entire response among the group classified as unconstrained to moral hazard, both of these misclassification errors lead to underestimation of the liquidity effect relative to moral hazard.

\section{B. Data}

I use data from the Survey of Income and Program Participation (SIPP) panels spanning 1985-2000. Each SIPP panel surveys households at 4month intervals for 2-4 years. Relative to other widely used data sets such as the Current Population Survey and the Panel Study on Income Dynamics, the main benefits of the SIPP are the availability of asset data, weekly data on employment status, data on UI benefit receipt, and large sample size.

Starting from the universe of job separations in the pooled SIPP panels, I restrict attention to prime-age males who $(a)$ report searching for a job, $(b)$ are not on temporary layoff, $(c)$ have at least 3 months of work history in the survey (so that preunemployment wages can be computed), and $(d)$ took up UI benefits within 1 month after job loss. ${ }^{21}$ Details on the sample construction and SIPP database are given in Appendix B. The restrictions leave 4,560 unemployment spells in the core analysis sample. Asset data are generally collected only once in each panel, so preunemployment asset data are available for approximately half of these observations.

The first column of table 1 gives summary statistics for the core sample. Monetary values are in real 1990 dollars in this and all subsequent tables. The median UI recipient is a high school graduate and has preUI gross annual earnings of $\$ 20,711$. Perhaps the most striking statistic is preunemployment wealth: median liquid wealth net of unsecured debt is only $\$ 128$, suggesting that many unemployed individuals may not be in a position to smooth consumption while unemployed.

Information on UI laws was obtained from the Employment and Training Administration's Significant Provisions of State Unemployment Insurance

\footnotetext{
${ }^{21}$ Restricting the sample to those who take up UI could lead to selection bias because the take-up decision is endogenous to the benefit level (Anderson and Meyer 1997). I find that the elasticity of take-up with respect to the benefit level is similar across the constrained and unconstrained groups, suggesting that endogeneity is unlikely to be responsible for the heterogeneous effects estimated below.
} 
TABLE 1

Summary Statistics by Wealth Quartile for SIPP Sample

\begin{tabular}{|c|c|c|c|c|c|}
\hline & \multirow[b]{2}{*}{ POOLED } & \multicolumn{4}{|c|}{ Net Liquid Wealth Quartile } \\
\hline & & $\begin{array}{c}<-\$ 1,115 \\
(1)\end{array}$ & $\begin{array}{c}-\$ 1,115-\$ 128 \\
(2)\end{array}$ & $\begin{array}{c}\$ 128-\$ 13,430 \\
\text { (3) }\end{array}$ & $\begin{array}{c}>\$ 13,430 \\
(4)\end{array}$ \\
\hline & \multicolumn{5}{|c|}{ Prior to or at Job Loss } \\
\hline Mean annual wage & $\$ 20,711$ & $\$ 19,638$ & $\$ 15,971$ & $\$ 20,950$ & $\$ 26,726$ \\
\hline $\begin{array}{l}\text { Median annual } \\
\text { wage }\end{array}$ & $\$ 17,780$ & $\$ 17,188$ & $\$ 14,346$ & $\$ 18,584$ & $\$ 23,866$ \\
\hline Age & 37.0 & 35.5 & 35.2 & 36.7 & 41.7 \\
\hline Years of education & 12.1 & 12.2 & 11.2 & 12.2 & 13.1 \\
\hline Percent married & $61 \%$ & $64 \%$ & $59 \%$ & $60 \%$ & $63 \%$ \\
\hline \multirow[t]{2}{*}{$\begin{array}{l}\text { Percent spouse } \\
\text { working }\end{array}$} & $37 \%$ & $40 \%$ & $28 \%$ & $40 \%$ & $44 \%$ \\
\hline & \multicolumn{5}{|c|}{ After Layoff } \\
\hline \multirow{5}{*}{$\begin{array}{l}\text { Weekly individual } \\
\text { unemployment } \\
\text { benefits } \\
\text { Individual replace- } \\
\text { ment rate } \\
\text { Mean unemploy- } \\
\text { ment duration } \\
\text { (weeks) } \\
\text { Median unemploy- } \\
\text { ment duration }\end{array}$} & $\$ 166$ & $\$ 163$ & $\$ 152$ & $\$ 167$ & $\$ 184$ \\
\hline & $49 \%$ & $50 \%$ & $50 \%$ & $49 \%$ & $47 \%$ \\
\hline & 18.3 & 18.0 & 19.1 & 17.6 & 19.4 \\
\hline & 15.0 & 15.0 & 17.0 & 14.0 & 17.0 \\
\hline & \multicolumn{5}{|c|}{ Assets and Liabilities } \\
\hline Mean liquid wealth & $\$ 22,701$ & $\$ 1,536$ & $\$ 502$ & $\$ 5,898$ & $\$ 87,912$ \\
\hline $\begin{array}{l}\text { Median liquid } \\
\text { wealth }\end{array}$ & $\$ 1,763$ & $\$ 466$ & $\$ 0$ & $\$ 4,273$ & $\$ 53,009$ \\
\hline $\begin{array}{l}\text { Mean unsecured } \\
\text { debt }\end{array}$ & $\$ 3,964$ & $\$ 10,008$ & $\$ 697$ & $\$ 1,752$ & $\$ 3,171$ \\
\hline $\begin{array}{l}\text { Median unsecured } \\
\text { debt }\end{array}$ & $\$ 960$ & 5,659 & $\$ 0$ & $\$ 35$ & $\$ 835$ \\
\hline Mean home equity & $\$ 31,053$ & $\$ 19,768$ & $\$ 12,866$ & $\$ 30,441$ & $\$ 62,663$ \\
\hline $\begin{array}{l}\text { Median home } \\
\text { equity }\end{array}$ & $\$ 8,143$ & $\$ 2,510$ & $\$ 0$ & $\$ 11,794$ & $\$ 48,900$ \\
\hline $\begin{array}{l}\text { Percent with } \\
\text { mortgage }\end{array}$ & & & $27 \%$ & $49 \%$ & $50 \%$ \\
\hline Percent renters & $39 \%$ & $43 \%$ & $61 \%$ & $35 \%$ & $16 \%$ \\
\hline
\end{tabular}


Laws (various years) and supplemented with information directly from individual states. Unfortunately, measurement error and inadequate information about preunemployment wages for many claimants make it difficult to predict each claimant's benefit level precisely. I therefore use three independent methods to proxy for each claimant's (unobserved) actual UI benefits. First, I use average benefits for each state/ year pair obtained from the Department of Labor in lieu of each individual's actual UI benefit amount. Second, I proxy for the actual benefit using maximum weekly benefit amounts, which are the primary source of variation in benefit levels across states, since most states replace 50 percent of a claimant's wages up to a maximum benefit level. Third, I simulate each individual's weekly UI benefit using a two-stage procedure. In the first stage, I predict each claimant's preunemployment annual income using education, age, occupation, and other demographics. In the second stage, I predict each claimant's unemployment benefits using a simulation program that assigns each claimant a benefit on the basis of the predicted wage, state, and year of claim. See Appendix $B$ for further details on the motivation for and implementation of this two-stage procedure.

\section{Results}

\section{Graphical Evidence and Nonparametric Tests}

I begin by providing graphical evidence on the effect of unemployment benefits on durations in constrained and unconstrained groups. First consider the asset proxy for constraints. I divide households into four quartiles on the basis of their net liquid wealth. Table 1 shows summary statistics for each of the four quartiles. Households in the lower net liquid wealth quartiles are poorer and less educated, but the differences between the four groups are not very large. As a result, UI benefit levels are fairly constant across the groups. In particular, the replacement rate-defined as each individual's simulated unemployment benefit divided by his predicted wage-is close to 50 percent on average in all four quartiles. This similarity of benefit and income levels suggests that differences in benefit duration elasticities across the quartiles are unlikely to be driven purely by differences in the levels around which the elasticities are estimated.

Figure 3 shows the effect of UI benefits on job-finding rates for households in each of the four quartiles of the net wealth distribution. Since ex post asset levels are endogenous to duration of unemployment, households for which asset data are available only after job loss are excluded when constructing these figures. Including these households turns out to have little effect on the results, as we will see below in the 
regression analysis. I construct the figures by first dividing the full sample of UI claimants into two categories: those that are in state/year pairs that have average weekly benefit amounts above the sample median and those below the median. I then plot Kaplan-Meier survival curves for these two groups using the households in the relevant net wealth quartile. Note that the differences in average individual replacement rates between the low- and high-benefit groups are fairly similar in the four quartiles.

These and all subsequent survival curves plotted using the SIPP data are adjusted for the "seam effect" in panel surveys. Individuals are interviewed at 4-month intervals in the SIPP and tend to repeat answers about weekly job status in the past 4 months. Consequently, a disproportionately large number of transitions in labor force status are reported on the "seam" between interviews, leading to artificial spikes in the hazard rate at 4 and 8 months. These spikes are smoothed out by fitting a Cox model with a time-varying indicator for being on a seam between interviews and then recovering the baseline hazards to construct a seam-adjusted Kaplan-Meier curve. The resulting survival curves give the probability of remaining unemployed after $t$ weeks for an individual who never crosses an interview seam. The results are similar if the raw data are used without adjusting for the seam effect.

Figure $3 a$ shows that higher UI benefits lead to much lower jobfinding rates for individuals in the lowest wealth quartile. For example, 15 weeks after job loss, 55 percent of individuals in low-benefit state/ years are still unemployed, compared with 68 percent of individuals in high-benefit state/years. A nonparametric Wilcoxon test rejects the null hypothesis that the survival curves are identical with $p<0.01 .^{22}$ Figure $3 b$ constructs the same survival curves for the second wealth quartile. UI benefits have a smaller effect on durations in this group. At 15 weeks, 63 percent of individuals in the low-benefit group are still unemployed, versus 70 percent in the high-benefit group. Equality of the survival curves is rejected with $p=0.04$. Figures $3 c$ and $d$ show that the effect of UI on durations virtually disappears in the third and fourth quartiles of the wealth distribution. Not surprisingly, the equality of the survival curves is not rejected in these two groups. The fact that UI has little effect on durations in the unconstrained groups suggests that it induces little moral hazard among these households.

The secondary proxies confirm these results. Figure $4 a$ shows that UI benefits have a clear, statistically significant effect on job-finding rates among households that are paying off mortgages prior to job loss. In contrast, figure $4 b$ shows that the effect is smaller for households that

\footnotetext{
${ }^{22}$ The nonparametric test is conducted on the raw data because adjusting for the seam effect requires a parametric assumption about the hazard rate.
} 

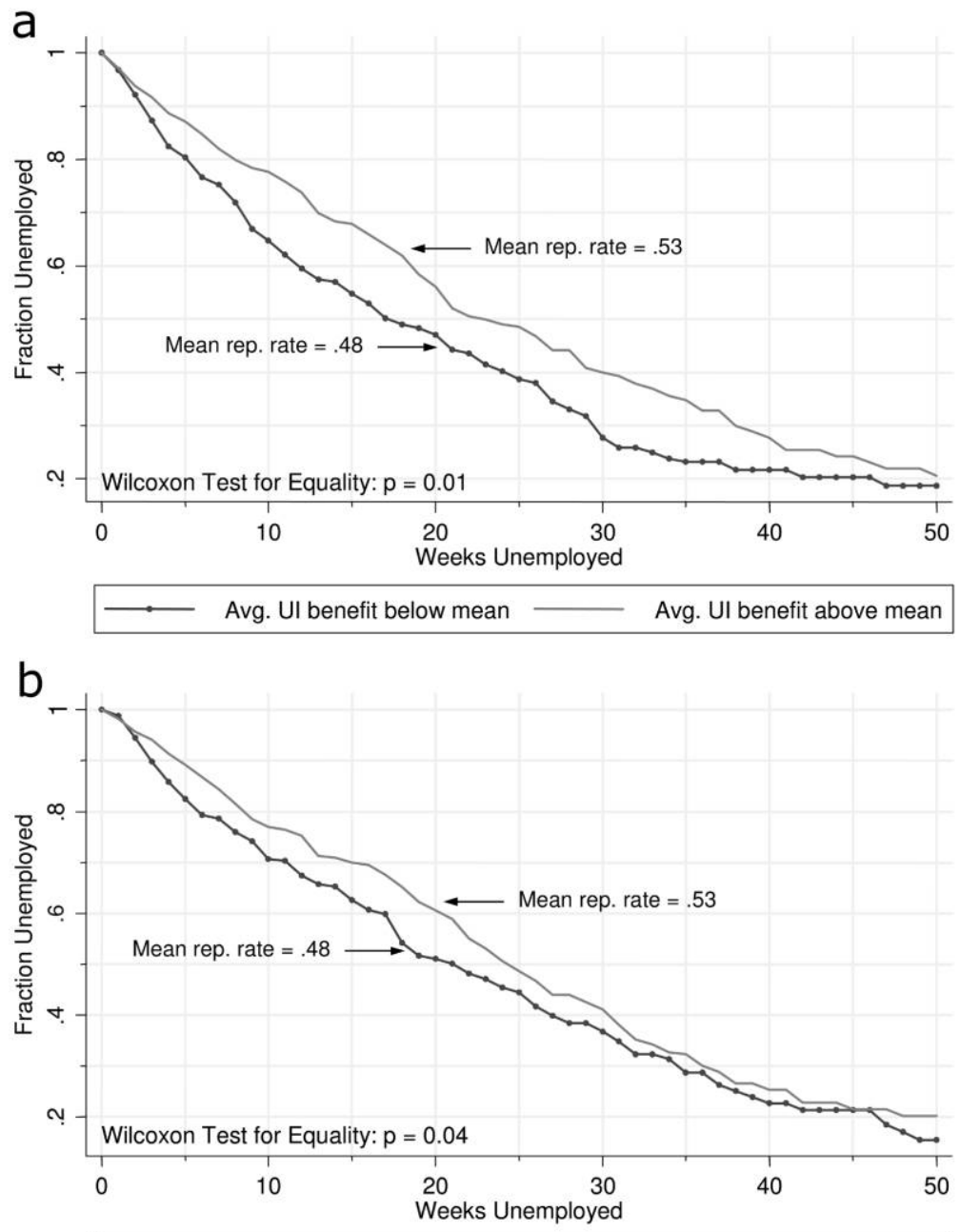

Avg. UI benefit below mean _ـ Avg. UI benefit above mean

FIG. 3.-Effect of UI benefits on durations. $a$, Lowest quartile of net wealth. $b$, Second quartile of net wealth. $c$, Third quartile of net wealth. $d$, Highest quartile of net wealth. The sample for panels $a$ and $b$ consists of observations in the core SIPP sample for which preunemployment wealth data are available. See table 1 for the definition of the core sample and the definition of net liquid wealth. Each panel plots Kaplan-Meier survival curves for two groups of individuals: those in state/year pairs with average weekly benefit amounts below the sample mean and those in state/year pairs with weekly benefit amounts above the mean. The mean replacement rate is the average individual-level predicted benefit divided by wage for observations in the relevant group. Survival curves are adjusted for a seam effect by fitting a Cox model with a seam dummy and recovering baseline hazards. 

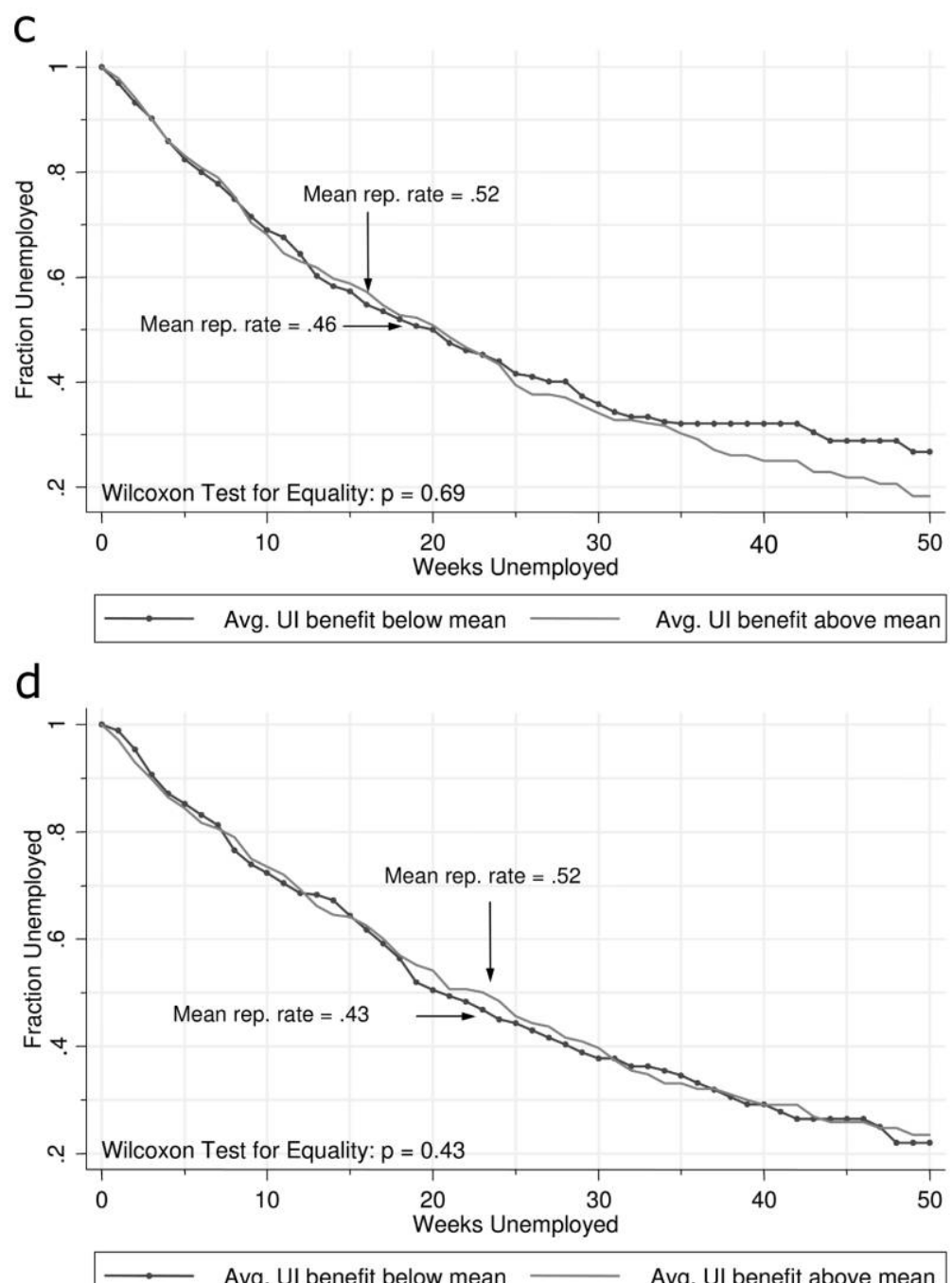

FIG. 3 (Continued)

are not paying off mortgages and are hence less constrained. ${ }^{23}$ Results are similar for the spousal work proxy: UI benefits have a much larger

${ }^{23}$ In contrast with the other proxies, the constrained types in this specification (homeowners with mortgages) have higher income, education, and wealth than the unconstrained types, who are primarily renters. This makes it somewhat less likely that the differences in the benefit elasticity of duration across constrained and unconstrained groups are spuriously driven by other differences across the groups such as income or education. 


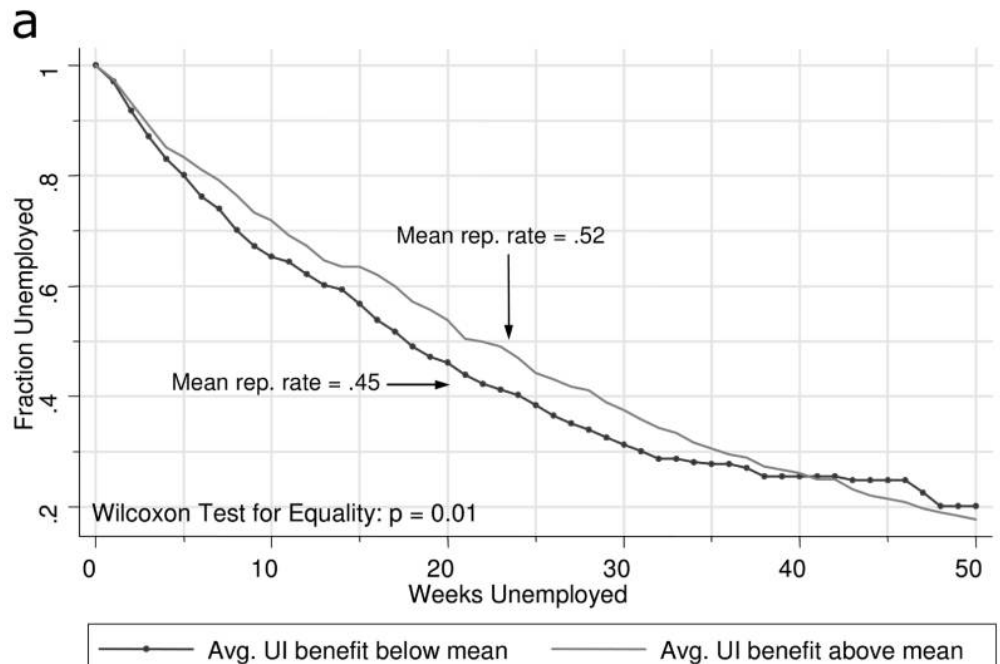

b

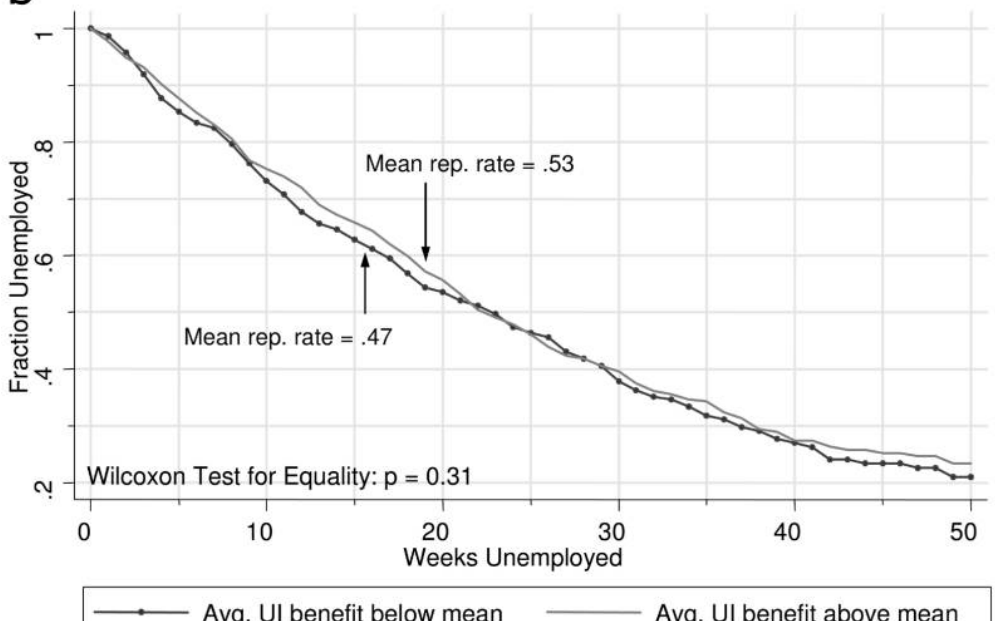

FIG. 4.-Effect of UI benefits on durations. $a$, Households with mortgages. $b$, Households without mortgages. These figures are constructed in the same way as figs. $3 a$ and $b$. Panel $a$ includes households that make mortgage payments; panel $b$ includes all others. Only observations with mortgage data prior to job loss are included. 
effect on job-finding hazards for single-earner families than for dualearner families (see Chetty 2005, fig. 2).

The preceding results show that the interaction effect of UI benefits and wealth (or other proxies) on durations is negative. An alternative approach to evaluating the importance of liquidity is to study the direct effect of the cross-sectional variation in wealth on durations, testing in particular if durations are an increasing and concave function of wealth. I focus on the variation in UI benefits because changes in UI laws are credibly exogenous to individuals' preferences. In contrast, conditional on demographics and income, cross-sectional variation in wealth holdings arises from heterogeneity in tastes for savings, confounding the effect of wealth on duration in the cross section. For example, UI claimants with higher assets are also likely to have lower discount rates or higher anticipated expenses (e.g., college tuition payments), and hence may be reluctant to deplete their assets to finance a longer spell of unemployment. ${ }^{24}$ In practice, I find no robust relationship between assets and unemployment durations in the cross section (as indicated by the mean durations by quartile reported in table 1), consistent with the results of Lentz (2008). This finding underscores the importance of using exogenous variation such as UI benefits for identification. The same issue also motivates the use of severance pay as a source of variation in wealth to identify the liquidity effect in Section IV.

\section{Hazard Model Estimates}

I evaluate the robustness of the graphical results by estimating a set of Cox hazard models in table 2. Let $h_{i, t}$ denote the unemployment exit hazard rate for individual $i$ in week $t$ of an unemployment spell, $\alpha_{t}$ the "baseline" hazard rate in week $t, b_{i}$ the unemployment benefit level for individual $i$, and $X_{i, t}$ a set of controls. Throughout, I censor durations at 50 weeks to reduce the influence of outliers and focus on search behavior in the year after job loss.

Since the welfare gain formula (14) calls for estimates of the effect of UI benefits on search behavior at the beginning of the spell $\left(\partial s_{0} / \partial b\right)$, I estimate hazard models of the following form:

$$
\log h_{i, t}=\alpha_{t}+\beta_{1} \log b_{i}+\beta_{2} t \times \log b_{i}+\beta_{3} X_{i, t}
$$

Here, the coefficient $\beta_{1}$ gives the elasticity of the hazard rate with respect to UI benefits at the beginning of the spell $(t=0)$ because the interaction term $t \times \log b_{i}$ captures any time-varying effect of UI benefits on

\footnotetext{
${ }^{24}$ More generally, wealthier individuals may have unobserved characteristics (e.g., skills, job search technologies) that lead to different durations for reasons unrelated to their wealth.
} 


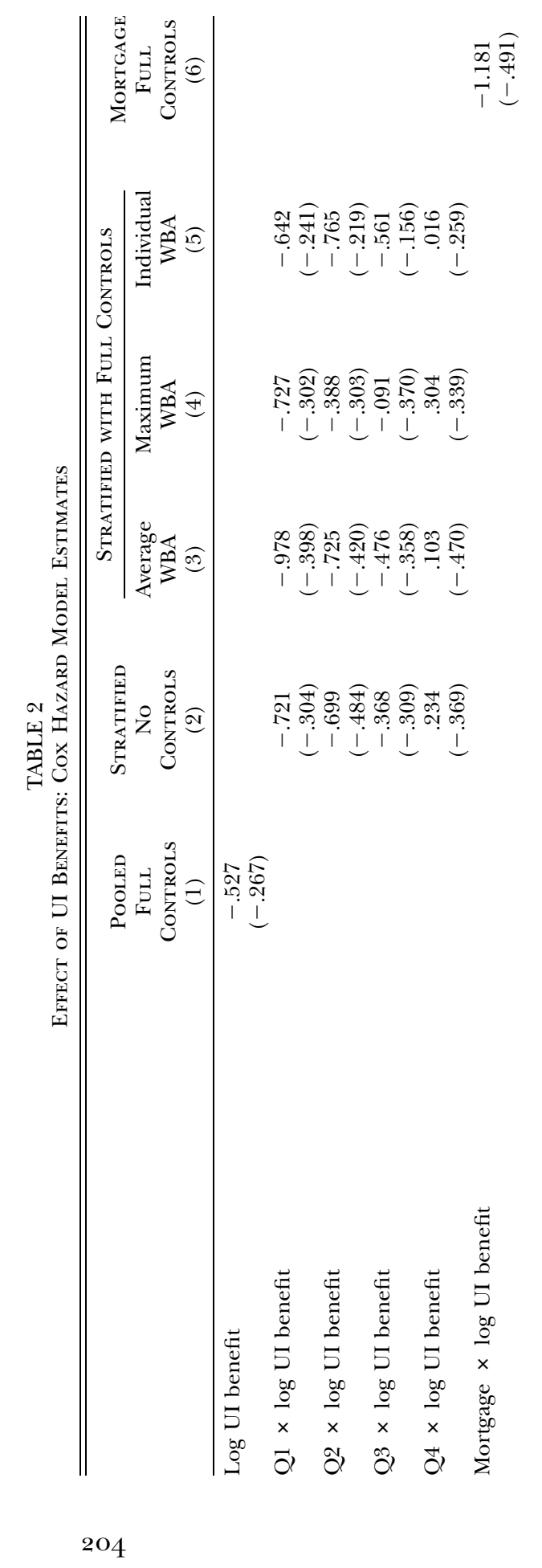




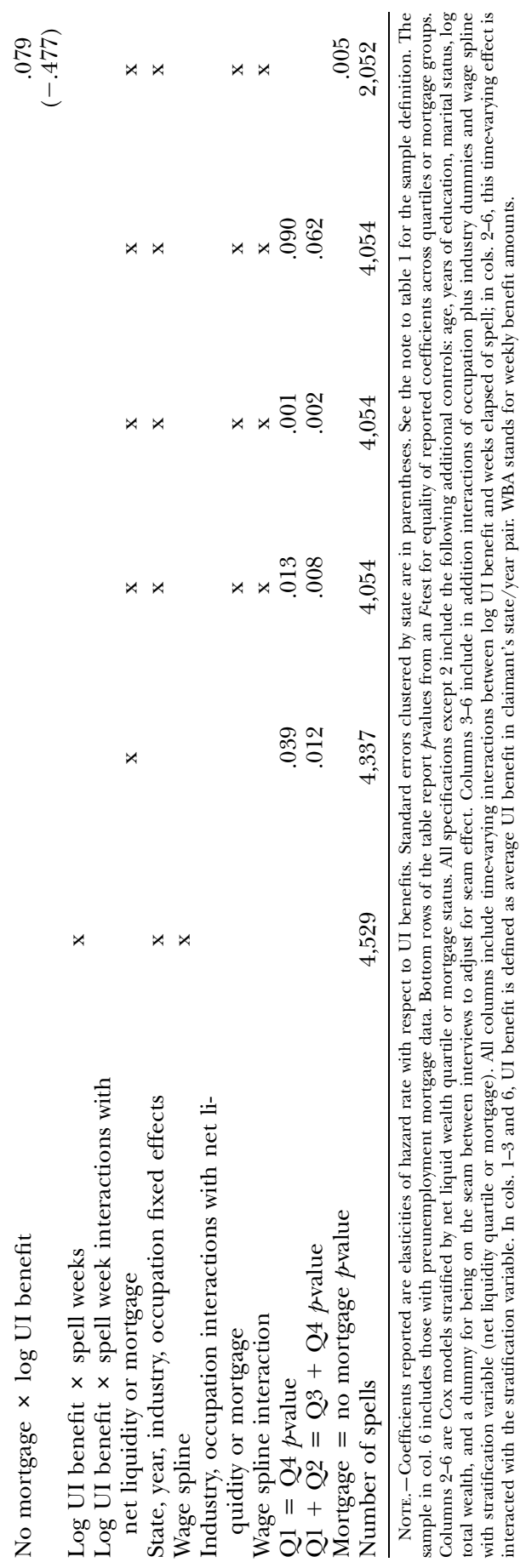

205 
hazards. Note that the search model does not make a clear prediction about the sign of $\beta_{2}$. The effect of UI benefits could diminish over time $\left(\beta_{2}<0\right)$ because the number of weeks for which benefits remain available is falling. But $\beta_{2}$ could also be positive because households are increasingly constrained and thus more sensitive to cash on hand late in the spell. In practice, there is no robust, statistically significant pattern in the $\beta_{2}$ coefficients across the quartiles, and I therefore do not report them in table 2 in the interest of space. ${ }^{25}$

I first estimate (17) on the full sample to identify the unconditional effect of UI on the hazard rate. In this specification, as in most others, I use the average UI benefit level in the individual's state/year pair to proxy for $b_{i}$ in light of the measurement error issues discussed above. This specification includes the following controls: state, year, industry, and occupation fixed effects; a 10-piece log-linear spline for the claimant's preunemployment wage; linear controls for total (illiquid + liquid) wealth, age, and education; and dummies for marital status and being on the seam between interviews to adjust for the seam effect. Standard errors in this and all subsequent specifications are clustered by state. The estimate in column 1 of table 2 indicates that a 10 percent increase in the UI benefit rate reduces the hazard rate by 5.3 percent in the pooled sample, consistent with the estimates of prior studies. The estimate of $\beta_{2}=0.001$ (standard error 0.008), indicating that there is no detectable variation in the UI benefit effect over the spell.

To examine the heterogeneity of the UI effect, I estimate separate coefficients for each of the four quartiles of the net wealth distribution. These specifications include all households for which asset data are available either before or after the spell. Consistent with the graphical evidence, the estimates are similar (but less precise) if only households with ex ante asset data are included.

Let $Q_{i, j}$ denote an indicator variable that is one if agent $i$ belongs to quartile $j$ of the wealth distribution. Let $\alpha_{t, j}$ denote the baseline jobfinding hazard for individuals in quartile $j$ in week $s$ of the unemployment spell. Columns 2-5 of table 2 report estimates of $\left\{\beta_{1}^{j}\right\}_{j=1,2,3,4}$ from the following stratified Cox model:

$$
\log h_{i t j}=\alpha_{t, j}+\beta_{1}^{j} Q_{i, j} \log b_{i}+\beta_{2}^{j} Q_{i, j}\left(t \times \log b_{i}\right)+\beta_{3} X_{i t j} .
$$

In this equation, $\beta_{1}^{j}$ corresponds to the elasticity of the hazard rate with respect to UI benefits at $t=0$ in quartile $j$ of the net wealth distribution. Specification 2 of table 2 reports estimates of (18) with no controls (no $X)$. The effect of UI benefits declines monotonically with net wealth.

${ }^{25}$ The only stable pattern across the specifications is that $\beta_{2}$ is slightly negative in the highest wealth quartile (around -0.03). The reason could be that households that are initially unconstrained become increasingly liquidity constrained as they deplete their buffer stocks. 
Among households in the lowest quartile of net wealth, a 10 percent increase in UI benefits reduces the hazard rate by 7.2 percent. In contrast, there is a much weaker association between the level of UI benefits and the hazard among households in the third and fourth quartiles of net wealth. The null hypothesis that UI benefits have the same effect on hazard rates in the first and fourth quartiles is rejected with $p<$ 0.05 , as is the null hypothesis that the mean UI effect for households with below-median wealth is the same as that for households with abovemedian wealth.

Specification 3 replicates 2 with the full set of controls used in column 1 , including state and year fixed effects so that the coefficients are identified from changes in UI laws within states rather than cross-state comparisons. This specification also includes interactions of the wage spline and industry/occupation dummies with the wealth quartile indicators, allowing these variables to have different effects across the quartiles. The pattern of the coefficients is unchanged, but the magnitudes of the coefficients in the first three quartiles is larger, perhaps because exogenous changes in UI laws are more effectively isolated when the controls are included.

In specifications 4 and 5, I explore robustness to changes in the definition of $b_{i}$. Both of these specifications include the control set used in specification 3. Column 4 uses the maximum UI benefit level in individual $i$ 's state/year and column 5 uses the simulated benefit for each individual $i$ using the two-stage procedure described above. In the maximum benefit specification, the coefficient estimates are all smaller than their counterparts in specification 3 , but the pattern is preserved: the effect of benefits is larger for low-wealth individuals, and the hypothesis tests of equivalent effects in the lower and upper quartiles are both rejected with $p<0.01$. In the individual simulated benefit specification, UI benefits are estimated to have little effect on durations in the highest wealth quartile, and the elasticity estimates are declining in quartiles 2-4. However, the estimate for the first quartile is smaller than that in the second quartile, breaking the monotonic declining pattern obtained with the other measures of benefits.

I have estimated a set of specifications analogous to (18) for the spousal work and mortgage proxies. An example is in column 6 of table 2, which reports estimates of the effect of UI benefits on job-finding hazards for households with and without a mortgage prior to job loss. This specification includes the same controls as in column 3, except that the relevant covariates are interacted with the mortgage indicator rather than with the asset quartiles. The estimates indicate that benefits have a considerably larger effect on durations among households that have mortgages. See table 3 in Chetty (2005) for additional estimates using the spousal work and mortgage proxies. 
I have also fit a variety of other specifications to further probe the robustness of the results (Chetty 2005, table 2b). The estimates are similar when high-income individuals are excluded or temporary layoffs are included. Results are also similar with controls for the average wage income in each state and year from the Bureau of Labor Statistics or when the wealth quartiles are defined in terms of wealth divided by wages. In contrast to liquid wealth, I find no systematic link between home equity and the benefit duration elasticity. This is consistent with the importance of liquidity, since accessing home equity is difficult when one is unemployed (Hurst and Stafford 2004). Finally, I find no relationship between the level of benefits and durations for a control group of individuals who do not receive UI. This "placebo test" supports the identification assumption that the variation in UI benefits is orthogonal to unobservable determinants of durations.

In summary, the SIPP data indicate that the link between unemployment benefits and durations documented in earlier studies is driven by a subset of the population that has limited ability to smooth consumption. This pattern is suggestive of a substantial liquidity effect. As shown in figure 1, if one were to assume that substitution effects, $\left.\left(\partial s_{0} / \partial w\right)\right|_{B}$, are similar across unconstrained and constrained groups, this evidence would be sufficient to infer that liquidity effects are large. However, this assumption may be untenable: constrained households might have different preferences (locally or globally) that generate larger substitution effects than unconstrained households. I therefore turn to a second empirical strategy to identify the magnitude of the liquidity effect.

\section{Empirical Analysis II: Severance Pay and Durations}

\section{A. Estimation Strategy}

The ideal way to estimate the liquidity effect would be a randomized experiment in which some job losers are given lump-sum grants or annuity payments but others are not. Lacking such an experiment, I exploit variation in severance pay policies across firms in the United States. ${ }^{26}$ Severance payments are made either as lump-sum grants at the time of job loss or in the form of salary continuation (short-duration

${ }^{26}$ Receipt of severance pay intended to supplement UI benefits typically does not affect eligibility for UI, although some states can delay benefits if the claimant receives "wages in lieu of notice" (Kodrzycki 1998; McCulloch 1998). In Pennsylvania, the unemployment compensation law explicitly states that severance pay does not affect UI benefits (Pennsylvania Department of Labor and Industry 2007). Restricting the analysis to the Pennsylvania data set below yields results similar to those obtained for the pooled sample. 
annuities). ${ }^{27}$ All severance packages are unconditional payments that do not distort marginal incentives to search for a new job. Thus, any causal effect of severance pay on unemployment durations reflects a pure liquidity effect.

The most common severance policy is one week of wages per year of service at the firm. Some companies have flatter or steeper profiles with respect to job tenure, and others make no severance payments at all (Lee Hecht Harrison 2001). Many companies have minimum job tenure thresholds to be eligible for severance pay, ranging from 3 to 5 years. There is little variation in severance packages within a given firm and tenure bracket. Hence, conditional on tenure, the variation in receipt of severance pay is driven primarily by differences in policies across firms.

I estimate the effect of severance pay using hazard models similar to those above:

$$
\log h_{i, t}=\alpha_{t}+\theta_{1} \operatorname{sev}_{i}+\theta_{2} \operatorname{sev}_{i} \times t+\gamma X_{i, t}
$$

where $\operatorname{sev}_{i}$ is an indicator for receipt of severance pay. The coefficient $\theta_{1}$ identifies the effect of cash grants on job-finding hazards at the beginning of the spell if receipt of severance pay is orthogonal to other determinants of durations. After estimating the baseline model, I evaluate this orthogonality condition.

\section{B. Data}

The data for this portion of the study come from two surveys conducted by Mathematica on behalf of the Department of Labor. The data sets contain information on unemployment durations, demographic characteristics, and data on receipt of severance pay. The first data set is a representative sample of job losers in Pennsylvania in 1991. The second data set is a sample of unemployment durations in 25 states in 1998 that oversamples UI exhaustees. I reweight the data using the sampling weights to obtain estimates for a representative sample of job losers.

For comparability to the preceding results, I make the same exclusions after pooling the two data sets. I include only prime-age males and discard all individuals who expected a recall at the time of layoff (including temporary layoffs does not affect the results, as above). These exclusions leave 2,441 individuals in the sample, of whom 471 (18 percent) report receiving a severance payment. Details on the Mathematica data sets and sample construction are given in Appendix C.

\footnotetext{
${ }^{27}$ Since the form of the severance payment cannot be determined in the data, I treat all severance payments as cash grants. To the extent that the severance is paid as salary continuation, the formula for $d W / d b$ in corollary 1 will be more accurate because there is less reliance on the approximate annuity conversion in (13).
} 
TABLE 3

Summary Statistics by Severance Receipt for Mathematica Sample

\begin{tabular}{|c|c|c|c|}
\hline & Pooled & $\begin{array}{c}\text { No Severance } \\
(-.81)\end{array}$ & $\begin{array}{c}\text { Severance } \\
(.19)\end{array}$ \\
\hline & \multicolumn{3}{|c|}{ Prior to or at Job Loss } \\
\hline Mean annual wage & $\$ 28,149$ & $\$ 26,213$ & $\$ 37,174$ \\
\hline Median annual wage & $\$ 20,848$ & $\$ 19,347$ & $\$ 30,693$ \\
\hline Age & 36.2 & 35.2 & 40.6 \\
\hline Percent dropouts & $14 \%$ & $15 \%$ & $6 \%$ \\
\hline Percent college graduates & $17 \%$ & $13 \%$ & $34 \%$ \\
\hline Percent married & $58 \%$ & $56 \%$ & $68 \%$ \\
\hline Mean job tenure (years) & 4.5 & 3.8 & 8.1 \\
\hline \multirow[t]{2}{*}{ Median job tenure (years) } & 1.9 & 1.5 & 4.8 \\
\hline & \multicolumn{3}{|c|}{ After Layoff } \\
\hline Weekly unemployment benefits & $\$ 198$ & $\$ 190$ & $\$ 236$ \\
\hline Replacement rate & $49 \%$ & $51 \%$ & $43 \%$ \\
\hline Mean unemployment duration & 24.3 & 24.0 & 25.6 \\
\hline Median unemployment duration & 20.0 & 20.0 & 22.0 \\
\hline Mean compensated duration & 15.8 & 15.3 & 18.2 \\
\hline Median compensated duration & 16.0 & 16.0 & 20.0 \\
\hline \multicolumn{4}{|c|}{$\begin{array}{l}\text { NOTE.-Table entries are means unless otherwise noted. Data are from surveys of job losers conducted by Mathematica. } \\
\text { Sample includes prime-age male UI claimants who are not on temporary layoff. Pooled sample size is } 2,441 \text { observations. } \\
\text { See App. C for details. Data are reweighted using sampling probabilities to yield estimates for a representative sample } \\
\text { of job losers. Preunemployment job tenure is the number of years spent working at the firm from which the worker } \\
\text { was laid off. Weekly unemployment benefit is actual individual benefit based on UI records. Replacement rate is weekly } \\
\text { benefit times } 52 \text { divided by annual wage. Unemployment duration is time elapsed from the end of the last job to the } \\
\text { start of the next job. Compensated duration is weeks of UI collected. All monetary values are in real } 1990 \text { dollars. }\end{array}$} \\
\hline
\end{tabular}

Two measures of "unemployment duration" are available in these data sets: (1) an administrative record of the number of weeks for which UI benefits were paid and (2) the number of weeks from the end date of the individual's previous job to the (self-reported) start of the next job. For consistency with the SIPP estimates, I focus on the second measure here. Results are similar, and more precisely estimated, using the administrative measure.

Table 3 shows summary statistics for severance pay recipients and nonrecipients. The sample generally looks quite similar on observables to the SIPP sample used above. Given the minimum tenure eligibility requirement, it is not surprising that severance pay recipients have much higher median job tenures than nonrecipients. Correspondingly, severance pay recipients are older and higher in observable characteristics than nonrecipients. These differences underscore why one must be careful in drawing causal inferences from comparing severance pay recipients and nonrecipients.

\section{Results}

I begin again with graphical evidence. Figure 5 shows Kaplan-Meier survival curves for two groups of individuals: those who received sev- 


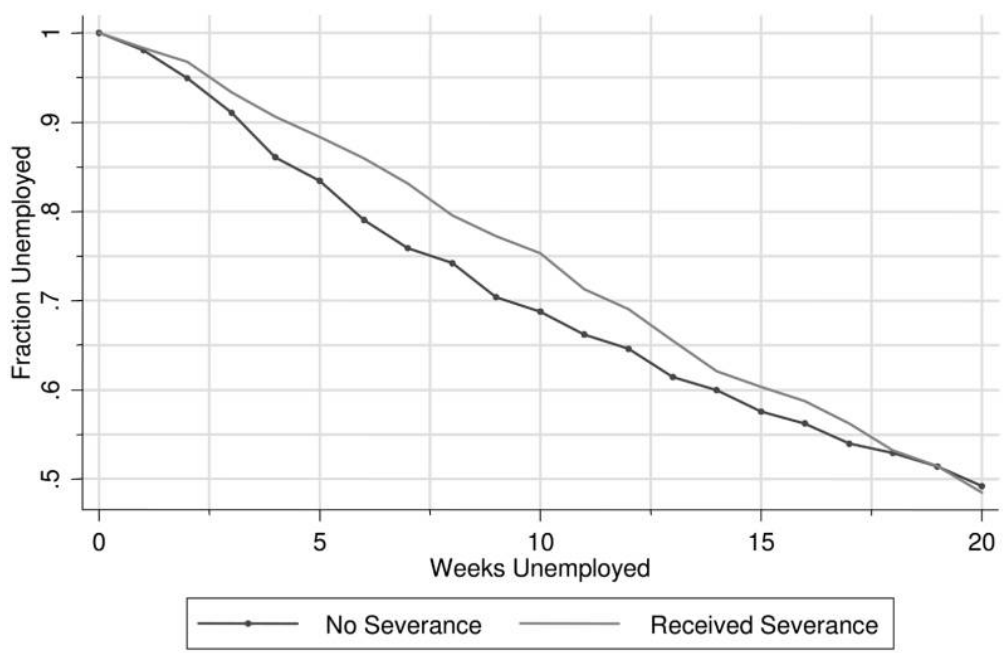

Fig. 5.-Effect of severance pay on durations. Data are from Mathematica surveys; see the note to table 3 for additional details on data and sample definition. Data are reweighted using sampling probabilities to yield estimates for a representative sample of job losers. Kaplan-Meier survival curves are plotted for two groups of individuals: those who received a severance payment at the time of job loss and those who did not. Survival curves are adjusted for the effect of preunemployment job tenure on durations by fitting a Cox model and recovering baseline hazards as described in the text.

erance pay and those who did not. Since preunemployment job tenure is an important determinant of severance pay and is also highly positively correlated with durations, I control for it throughout the analysis. These survival curves have been adjusted for tenure by fitting a Cox model with tenure as the only regressor and recovering the baseline hazards for each group. Severance pay recipients have significantly lower jobfinding hazards. As a result, 68 percent of individuals who received severance pay remain unemployed after 10 weeks, compared with 75 percent among those who received no severance payment. ${ }^{28}$

An obvious concern in interpreting this result as evidence of a liquidity effect is that it may reflect correlation rather than causality because severance pay recipients differ from nonrecipients. For instance, firms that offer severance packages might do so because their workers have accumulated more specific human capital and are likely to take a long time to find a suitable new job. This would induce a spurious correlation between severance pay and durations in the cross section.

I use three approaches to investigate the causality of severance pay.

${ }^{28}$ This result is consistent with the findings of Kodrzycki (1998), who compares unemployment durations among severance pay recipients and nonrecipients for a sample of displaced workers who attended training programs. 
First, I investigate whether the effect of severance pay differs across constrained and unconstrained groups. The model in Section II indicates that severance pay-which is a minor fraction of lifetime wealthshould causally affect durations only among households that cannot smooth consumption. In contrast, alternative explanations such as the one proposed above would not necessarily predict a differential effect of severance pay across constrained and unconstrained households. Hence, the heterogeneity of the estimated severance pay effect yields insight into the causality of severance pay.

Implementing this test requires division of households into constrained and unconstrained groups. Unfortunately, the Mathematica surveys do not contain data on assets and the other proxies for constraint status used in the SIPP data. To overcome this problem, I predict assets for each household with an equation estimated using ordinary least squares (OLS) on the SIPP sample. The prediction equation is a linear function of age, wage, education, and marital status. I then divide households into two groups, above and below the median level of predicted assets. Note that results based on predicted assets (using the same prediction equation) and reported assets are similar in the SIPP data: the total elasticity of duration with respect to UI benefits is much larger among households with predicted assets below the median than for those above the median. Hence, the predicted asset measure succeeds in identifying the households whose search behavior is sensitive to UI benefits.

Figure 6 replicates figure 5 for the two groups. Figure $6 a$ shows that receipt of severance pay is associated with a large increase in survival probabilities for constrained (low-asset) households. Figure $6 b$ shows that severance pay has a much smaller effect on search behavior for households that are likely to be wealthier. Results are similar if households are split into constrained and unconstrained groups on the basis of age or income alone. Results are also unaffected by changes in the functional form of the asset prediction equation, prediction via quantile regression instead of OLS, or trimming of outliers. The fact that severance pay affects durations only in the group of households that are sensitive to UI benefits (those who are likely to be constrained) supports the claim that liquidity effects drive a substantial portion of the UIduration link.

As a second approach to examining the causality of severance pay, I assess the sensitivity of the severance pay effect to controlling for observed heterogeneity. I estimate variants of the Cox model in (19), censoring all durations at 50 weeks as in the SIPP data. I first estimate a model with only a linear tenure control and a time-varying interaction of severance pay with weeks unemployed. I then estimate the model with the following control set: 10-piece linear splines for log preunem- 

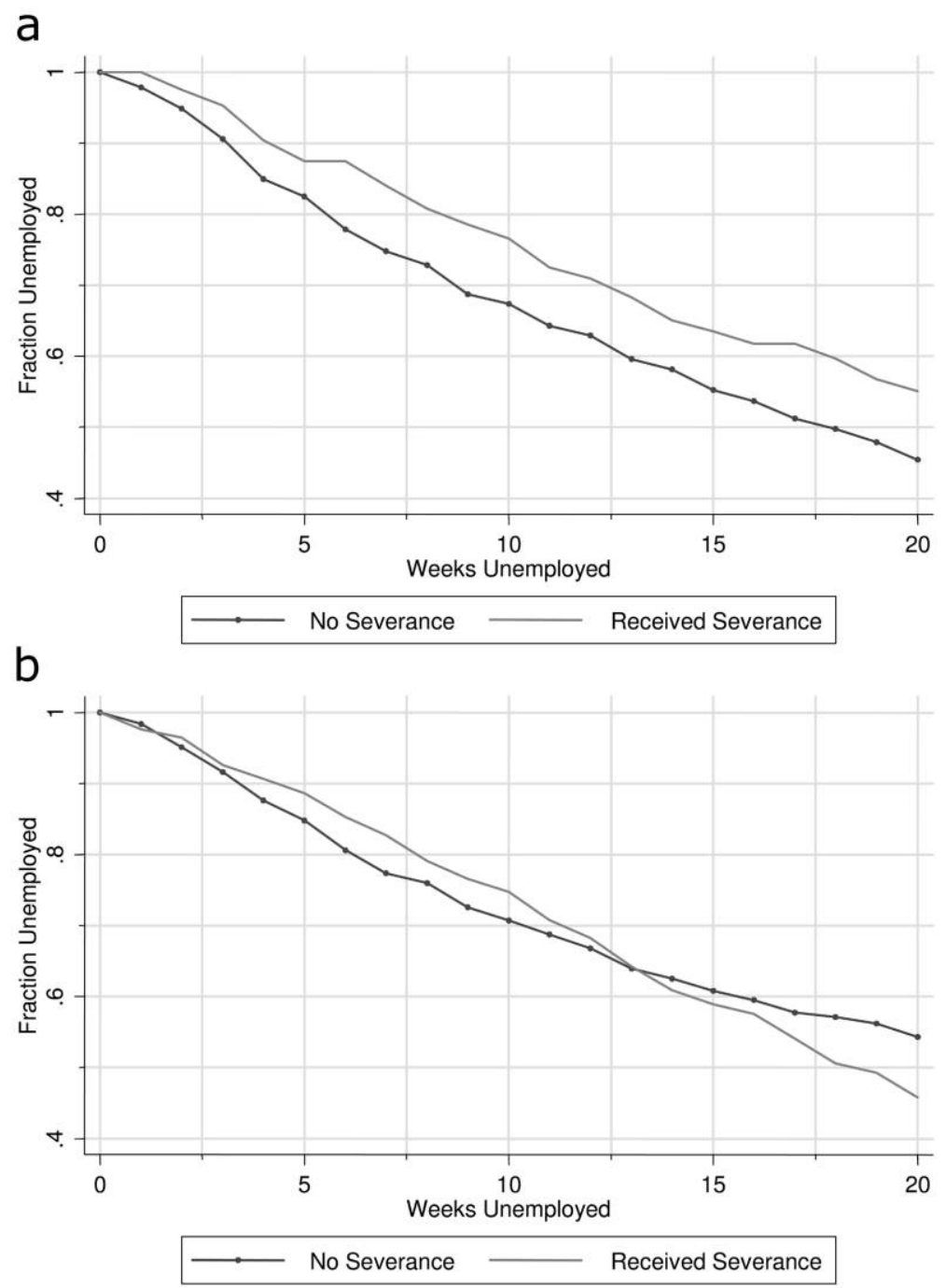

Fig. 6.-Effect of severance pay on durations: $a$, below median net wealth; $b$, above median net wealth. See fig. 5 for sample definition. Each panel is constructed in exactly the same way as fig. 5. Panel $a$ includes observations in which predicted net wealth is below the sample median; panel $b$ includes those above the median. Net wealth is predicted using a linear function of age, wage, education, and marital status that is estimated on the core SIPP sample as described in the text. 
TABLE 4

Effect of Severance Pay: Cox Hazard Model Estimates

\begin{tabular}{|c|c|c|c|c|c|c|}
\hline & \multicolumn{2}{|c|}{ Pooled } & \multicolumn{2}{|c|}{ By Wealth } & \multicolumn{2}{|c|}{$\begin{array}{c}\text { By Severance } \\
\text { Amount }\end{array}$} \\
\hline & $\begin{array}{l}\text { Tenure } \\
(1)\end{array}$ & $\begin{array}{l}\text { Full } \\
(2)\end{array}$ & $\begin{array}{l}\text { Tenure } \\
(3)\end{array}$ & $\begin{array}{l}\text { Full } \\
(4)\end{array}$ & $\begin{array}{l}\text { Tenure } \\
(5)\end{array}$ & $\begin{array}{c}\text { Full } \\
(6)\end{array}$ \\
\hline Severance pay dummy & $\begin{array}{l}-.179 \\
(.059)\end{array}$ & $\begin{aligned}-.233 \\
(.071)\end{aligned}$ & & & & \\
\hline $\begin{array}{l}\text { (Net liquidity }<\text { median }) \times \\
\text { severance pay }\end{array}$ & & & $\begin{array}{l}-.493 \\
(.086)\end{array}$ & $\begin{aligned}-.457 \\
(.099)\end{aligned}$ & & \\
\hline $\begin{array}{l}(\text { Net liquidity }>\text { median }) \times \\
\text { severance pay }\end{array}$ & & & $\begin{array}{c}.030 \\
(.058)\end{array}$ & $\begin{array}{r}-.088 \\
(.081)\end{array}$ & & \\
\hline $\begin{array}{l}(\text { Tenure }<\text { median }) \times \text { sever- } \\
\text { ance pay }\end{array}$ & & & & & $\begin{array}{c}-.099 \\
(.048)\end{array}$ & $\begin{aligned}-.143 \\
(.055)\end{aligned}$ \\
\hline $\begin{array}{l}(\text { Tenure }>\text { median }) \times \text { sever- } \\
\text { ance pay }\end{array}$ & & & & & $\begin{aligned}-.253 \\
(.084)\end{aligned}$ & $\begin{array}{r}-.340 \\
(.119)\end{array}$ \\
\hline Tenure spline & & $\mathrm{x}$ & & $\mathrm{x}$ & & $\mathrm{x}$ \\
\hline $\begin{array}{l}\text { State, industry, and occupa- } \\
\text { tion fixed effects }\end{array}$ & & $\mathrm{x}$ & & $\mathrm{x}$ & & $\mathrm{x}$ \\
\hline Wage spline & & $\mathrm{x}$ & & $\mathrm{x}$ & & $\mathrm{x}$ \\
\hline $\begin{array}{l}\text { Industry, occupation, and } \\
\text { wage spline interactions } \\
\text { with net liquidity }>\text { median } \\
\text { or tenure }>\text { median }\end{array}$ & & & & $\mathrm{x}$ & & $\mathrm{x}$ \\
\hline $\begin{array}{l}\text { Equality of coefficients } p \text { - } \\
\text { value }\end{array}$ & & & $<.01$ & $<.01$ & $<.01$ & .03 \\
\hline Number of spells & 2,441 & 2,428 & 2,441 & 2,428 & 2,441 & 2,428 \\
\hline
\end{tabular}

NoTE.-Coefficients reported can be interpreted as the percentage change in hazard rate associated with receipt of severance pay. Standard errors clustered by state are in parentheses. See the note to table 3 for the sample definition. The bottom row of specifications 3-6 reports $p$-values from an $F$ test for equality of coefficients across low- and highasset or low- and high-tenure groups. All specifications include a severance pay $\times$ spell week interaction variable to capture time-varying effects of severance pav. Columns 1, 3, and 5 include only a linear control for tenure at the prejob loss employer in addition. Columns 2, 4 , and 6 include the following controls in addition to those listed in the job lo table: age, nare 4 , In specifications 3 an 4, batio variable for whether the household's predicted assets are below the sample median. Assets are predicted using the SIPP data as described in the text. In specifications 5 and 6 , baseline hazards are stratified by tenure $<$ median. Tenure $<$ median is an indicator variable for whether the individual's job tenure is below 4.83 years (the median level tenure among severance pay recipients). Industry and occupation dummies and wage splines are interacted with the stratification variable in cols. 4 and 6.

ployment wage and job tenure; dummies for prior industry, occupation, and year; and controls for age, marital status, and education (using a dummy for dropout status and college graduation). Columns 1 and 2 of table 4 show that receipt of severance pay is estimated to lower the job-finding hazard at the beginning of the spell by $\theta_{1}=-18$ percent in the tenure control and $\theta_{1}=-23$ percent in the full-control specification. The estimated value of $\theta_{2}=1.3$ percent (standard error 0.2 percent) in both specifications. The effect of severance pay on search intensity diminishes over time, as one might expect if individuals deplete the grant over the course of the spell. 
Specifications 3 and 4 estimate separate severance pay coefficients for constrained (below-median predicted assets) and unconstrained (abovemedian) households. The baseline hazards are stratified by predicted wealth group (above/below-median), and the wage spline and industry/ occupation dummies are interacted with the predicted wealth dummy, as in the SIPP specifications. ${ }^{29}$ Consistent with figure 6 , the estimates indicate that severance pay reduces initial job-finding hazards in the low-wealth group by 46-49 percent but has little or no effect in the high-wealth group. The hypothesis that the effect of severance pay is the same in the low- and high-wealth groups is rejected with $p<0.01$. Predicting whether the individual is above or below median wealth directly in the first stage and interacting the predicted probability with the severance pay dummy when estimating the Cox model yield the same conclusion.

Finally, as a third robustness check, I test whether larger severance payments lead to longer unemployment durations. I implement this intensive margin test by investigating whether the effect of severance pay receipt differs by individuals' job tenure. Since the severance amount is an increasing function of job tenure, the indicator for receipt of severance pay should have a larger effect on durations among individuals with long job tenure. ${ }^{30}$ I divide the pooled sample (including both severance recipients and nonrecipients) into two groups-short and long tenure-on the basis of whether their job tenure is above or below the median for severance recipients (4.83 years). On the basis of data in Lee Hecht Harrison (2001), the mean severance amount conditional on receipt of severance is equivalent to two weeks of wages in the short-tenure group versus 13 weeks of wages in the long-tenure group (see App. C).

Columns 5 and 6 of table 4 replicate specifications 3 and 4, stratifying the baseline hazards by the short job tenure indicator and interacting it with the severance pay indicator. For individuals who have short job tenure, receipt of severance pay reduces initial job-finding hazards by 10-14 percent, compared with 25-34 percent for the long-tenure group. ${ }^{31}$ The hypothesis that the effect of severance pay is the same in the low- and high-tenure groups is rejected with $p<0.03$.

\footnotetext{
${ }^{29}$ Contrary to the SIPP specifications, I restrict the time interaction of severance pay with weeks unemployed to be the same across wealth groups here in order to increase power. Introducing an interaction yields similar point estimates but larger standard errors because the number of severance pay recipients is relatively small.

${ }^{30}$ Data on actual severance amounts are available for a subset of the Pennsylvania data set. I find a positive association between the reported amounts and durations, but the results are not statistically significant because of the small number of observations.

${ }^{31}$ An alternative interpretation of specifications 5 and 6 is that tenure is used as an instrument for the severance amount, with the direct effects of tenure on duration netted out by comparison to the group of nonrecipients. The correlation between job tenure
} 
Although these findings all point toward a substantial liquidity effect, the evidence cannot be viewed as fully conclusive because the variation in cash grants is not randomized. One might, for instance, be concerned that low-wealth workers with job-specific capital are especially likely to select into and stay at firms that offer severance payments, explaining the patterns in table 4 . It is reassuring that in a follow-up study that exploits quasi-experimental variation in severance payments created by a discontinuity in the Austrian severance pay system, Card et al. (2007) document a substantial effect of severance pay on durations, consistent with the evidence here. Further research along these lines is needed to obtain more precise and compelling estimates of the liquidity effect in the United States.

\section{Calibration: Welfare Implications}

I now use the hazard model estimates to calculate the average liquidity to moral hazard ratio in the population and the average welfare gain from raising $b$. Let $h_{0}$ denote the job-finding hazard in the first week for an agent who receives the mean UI benefit $\bar{b}$ and does not receive a severance payment. Let $h_{1}^{s}$ denote the hazard for an individual who receives the severance payment and $h_{1}^{b}$ denote the hazard for an individual whose UI benefit level is doubled. Using the approximation in (13), we obtain

$$
\left.\frac{\partial s_{0}}{\partial a}\right|_{B} / \frac{\partial s_{0}}{\partial b}=B \frac{\partial s_{0}}{\partial A} / \frac{\partial s_{0}}{\partial b}=\frac{B \bar{b}}{\bar{S}} \frac{\left(h_{1}^{s}-h_{0}\right) / h_{0}}{\left(h_{1}^{b}-h_{0}\right) / h_{0}}
$$

where $\bar{b}$ denotes the mean weekly UI benefit and $\bar{S}$ denotes the mean total value of the severance payment. On the basis of a survey of firms by Lee Hecht Harrison (2001), the mean severance payment equals 10.7 weeks of wages (see App. C). At the mean benefit level of $\bar{b}=0.5 \mathrm{w}$, this implies $\bar{S}=21.4 \bar{b}$; that is, receipt of severance pay is equivalent to an annuity payment of $\bar{b}$ per week for 21.4 weeks. The full-controls estimates from column 1 of table 2 and column 2 of table 4 imply $h_{1}^{b} / h_{0}=$ $\exp (-0.58)$ and $h_{1}^{s} / h_{0}=\exp (-0.23)$. It follows that

$$
\left.\frac{\partial s_{0}}{\partial a}\right|_{B} \frac{\partial s_{0}}{\partial b}=\frac{\exp (-0.23)-1}{\exp (-0.53)-1} \times \frac{26}{21.4}=0.6 .
$$

Around the level of benefits observed in the data $(b \approx 0.5 w)$, the liquidity

and durations is larger among severance pay recipients than among nonrecipients, which is consistent with a liquidity effect because the severance amount rises with job tenure for severance recipients. 
effect accounts for roughly 60 percent of the effect of marginal changes in the benefit level on unemployment durations.

Welfare gain of UI.-To calculate $\varepsilon_{D, b}$, recall from specification 1 of table 2 that the effect of benefits on the hazard rate does not vary significantly over the spell. From the approximation that the benefit elasticity and baseline hazard rates are constant, $D=1 / h$ and $\varepsilon_{D, b}=$ $-\left(\partial \log h_{0} / \partial \log b\right)=0.53 .{ }^{32}$ Shimer and Werning (2007) report that there are 7.7 million unemployed individuals and 135 million workers in the United States: $\sigma=135 / 142.7=0.946$. With the approximation that $\varepsilon_{D, b}=\varepsilon_{D_{B}, b}$, (14) yields

$$
\begin{aligned}
\frac{d W}{d b}(b=0.5 w) & =\frac{1-\sigma}{\sigma} \frac{D_{B}}{D}\left[\left.\frac{\partial s_{0}}{\partial a}\right|_{B} \mid\left(\left.\frac{\partial s_{0}}{\partial a}\right|_{B}-\frac{\partial s_{0}}{\partial b}\right)-\frac{\varepsilon_{D_{B},}}{\sigma}\right] \\
& =\frac{1-0.946}{0.946} \times \frac{15.8}{24.3} \times\left(\frac{0.6}{0.4}-\frac{0.53}{0.946}\right)=0.04 .
\end{aligned}
$$

Starting from $b=0.5 w$, a $\$ 1.00$ balanced-budget increase in the weekly benefit level would have raised each individual's utility by the equivalent of a 4 cent increase in the weekly wage, or about $\$ 2.00$ per year. When we aggregate over the population, the welfare gain of raising the UI benefit level by a dollar is equivalent to an increase in GDP of $\$ 290$ million. Starting from a mean benefit of $\$ 200$ per week, raising the benefit level by 10 percent would yield an aggregate welfare gain equivalent to about $\$ 5.9$ billion, roughly 0.05 percent of GDP.

It is important to recognize that these welfare gain calculations are valid only locally around $b=0.5 \mathrm{w}$. The liquidity effect and marginal welfare gain of UI will be larger when $b$ is low and small when $b$ is high, as illustrated in the numerical simulations in Section II. The local welfare gain estimate does tell us that the optimal wage replacement rate for UI exceeds 50 percent since $d W(b=0.5 w) / d b>0$. In addition, the evidence suggests that a replacement rate near 50 percent may be near optimal since $d W(b=0.5 w) / d b$ is small. ${ }^{33}$

It is interesting to compare the welfare implications of the revealed preference approach with those of previous studies. Hansen and Imrohoroglu (1992) find that the optimal replacement rate is 65 percent

\footnotetext{
${ }^{32}$ The elasticity $\varepsilon_{D, b}$ called for in (14) includes the effect of the change in $\tau$. The estimated elasticity does not fully include the effect of $\tau$ because the variation in UI benefits affects only some agents whereas taxes are levied more broadly. This discrepancy is likely to be quantitatively unimportant because the UI tax rate is very small $(\tau<0.01 w)$. In the numerical simulations, the elasticities with $\tau$ fixed and $\tau$ variable are virtually identical.

${ }^{33}$ This calculation ignores firm layoff behavior (Feldstein 1978; Topel 1983) and general equilibrium effects (Acemoglu and Shimer 1999). Generalizing the formula to account for these factors would be very valuable.
} 
if moral hazard is low but less than 10 percent if moral hazard is high in their baseline simulation. They conclude that evidence on moral hazard is needed to assess which case is relevant. The present paper provides empirical evidence that the low-moral hazard case is the relevant one and yields welfare implications consistent with Hansen and Imrohoroglu's simulation for that case. Baily (1978) and Gruber (1997) use a consumption-based exact identification approach to show that $\partial W(b=0.5 w) / \partial b<0$ using estimates of the consumption drop during unemployment. Indeed, their preferred calibrations using log utility imply an optimal benefit rate close to zero. The reason for the sharp discrepancy is that the liquidity effect estimated here is inconsistent with the relatively low degrees of risk aversion considered by Baily and Gruber. ${ }^{34}$ Shimer and Werning (2007) implement their reservation wage formula using an estimate of the sensitivity of reservation wages to benefits from Feldstein and Poterba (1984). They find that a $\$ 1.00$ increase in the benefit level would yield a net welfare gain equivalent to raising GDP by $\$ 2.4$ billion, four times larger than the estimate here. As Shimer and Werning observe, the credibility of existing reservation wage elasticity estimates is questionable, particularly in view of more recent evidence that UI benefit levels have little impact on subsequent wage rates (e.g., Card et al. 2007; van Ours and Vodopivec 2008).

Alternative policy instruments: loans.-In the analysis above, the unemployment benefit is used to facilitate both intertemporal smoothing and smoothing across states. A natural alternative instrument to resolve credit market failures is the provision of loans or UI savings accounts (Feldstein and Altman 1998; Shimer and Werning 2006). Although a formal analysis of optimal policy with multiple instruments is outside the scope of this paper, the numerical simulations can be used to gain some insight into how much of the welfare gain of UI could be obtained using loans.

Suppose that the government provides a loan of $\$ G$ upon job loss that must be repaid within $G_{T}$ weeks. With this loan, the agent's budget constraint is $A_{t} \geq-(L+G)$ for $t \leq G_{T}$ and $A_{t} \geq-L$ for $t>G_{T}$. Let us compare the welfare gain from increasing the government loan by $\$ B$,

${ }^{34}$ Recall that

$$
\left.\left.\frac{\partial s_{0}}{\partial a}\right|_{B}\right|_{B} \frac{\partial s_{0}}{\partial b}=0.6=\frac{u^{\prime}\left(c^{u}\right)-u^{\prime}\left(c^{e}\right)}{u^{\prime}\left(c^{u}\right)} \simeq \gamma \frac{c_{e}-c_{u}}{c_{u}},
$$

where $\gamma$ denotes the coefficient of relative risk aversion at $c_{u}$. Gruber estimates $c_{u} / c_{e}=$ 0.9 , which requires $\gamma \simeq 5$ to be consistent with a 60 percent liquidity effect. A strength of the formula proposed here is that it does not require estimates of risk aversion, which could plausibly be as high as $\gamma=5$ in the context of moderate shocks such as unemployment but much lower in other contexts (Chetty and Szeidl 2007). 


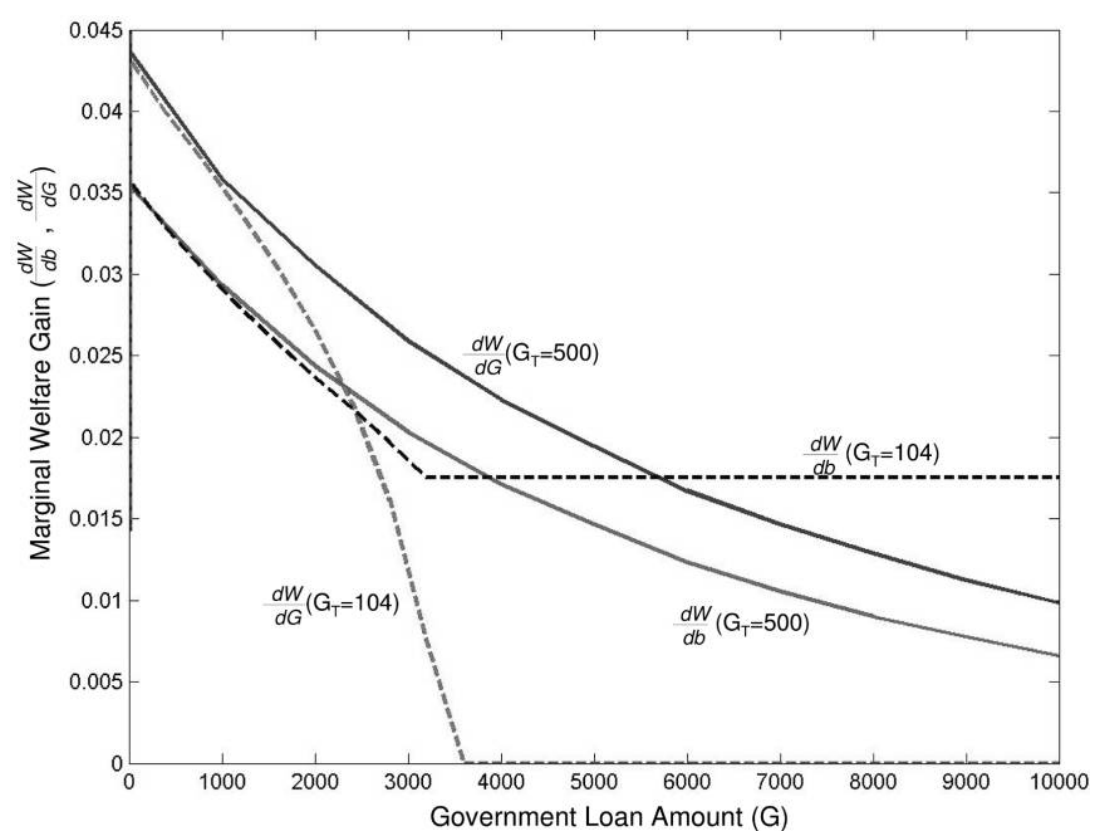

FIg. 7.-Welfare gain from loans vs. UI benefits. In this figure, the $d W / d b$ curves plot the welfare gain of raising the UI benefit $b$ by $\$ 1.00$ over the first 26 weeks as a function of the government loan amount. The $d W / d G$ curves plot the welfare gain of raising the government loan amount by $\$ B=\$ 26$ as a function of the loan amount. The solid curves are for a long-term loan that must be repaid upon death; the dashed curves are for a 2year loan. All the welfare gains are exact numerical simulations that assume $A_{0}=\$ 100$, $b=0.5 w$, and all other parameters as in fig. 1.

$$
\frac{d W}{d G}=B \frac{d J_{0}}{d G} / \frac{d J_{0}}{d w},
$$

with the welfare gain from raising the UI benefit by $\$ 1.00$ for $B$ periods,

$$
\frac{d W}{d b}=\frac{d J_{0}}{d G} \mid \frac{d J_{0}}{d w} .
$$

Assume $b=0.5 w$ and all other parameters as in figure 2. The solid curves in figure 7 plot $d W / d G$ and $d W / d b$ as a function of $G$ when the government loan has to be repaid by death $\left(G_{T}=T=500\right)$. The dashed curves plot $d W(G) / d G$ and $d W(G) / d b$ for a short-term loan $\left(G_{T}=104\right)$.

The simulations have three lessons. First, the welfare gains from providing long-term liquidity can be quite large. The welfare gain of initiating a long-term government loan when $b=0.5 w$ is $d W(G=$ $0) / d G=0.044$. The marginal welfare gain of increasing $b$ falls rapidly 
with $G$ : when $G=5,000, d W / d b$ is 40 percent of the value of $d W / d b$ when $G=0$. Substantial welfare gains can be achieved by correcting credit market failures while leaving insurance markets incomplete because unemployment shocks are small relative to permanent income.

Second, short-term loans are much less valuable than long-term loans. The marginal welfare gain of a loan that lasts for less than 11 months is zero in this numerical example because the private market borrowing limit $(L=-1,000)$ begins to bind only at $t=47$. The welfare gain from the 2-year loan plotted in the figure is close to the value of the permanent loan initially but declines rapidly as $G$ rises. Once the loan amount exceeds $\$ 3,600$, the marginal value of the loan becomes zero because the borrowing constraint becomes slack for $t \leq 104$. The UI benefit, in contrast, retains a marginal value of $d W / d b=0.018$ because consumption fluctuates significantly across states even when $G>$ $\$ 3,600$. Intuitively, a job loser is reluctant to take up a lot of short-term debt even though it would help him smooth consumption because of the risk of a long spell of unemployment (an example of precautionary savings behavior).

The final lesson pertains to the welfare value of using loans instead of the existing UI system. The long-term loan generates a strictly larger welfare gain than the UI benefit because UI has an efficiency cost, whereas loan provision is nondistortionary in this model. However, the difference in the welfare gain from a $\$ 1.00$ increase in $b$ and a comparable increase in even the first-best costless loan is less than 0.5 cent of weekly wages on average. The difference is small because the moral hazard distortion caused by UI is small in practice. It is therefore critical to quantify the moral hazard cost of loans to determine whether loans or subsidies for job search are a better policy to facilitate consumption smoothing.

Other policy implications.-Recent evidence that UI does not smooth consumption for households with high assets (e.g., Browning and Crossley 2001) has been interpreted as a point in favor of means-testing temporary income support programs. But UI does not affect unemployment durations significantly for this group either. Since means testing generates a distortionary incentive to save less, a universal benefit may maximize welfare. In addition, the evidence above implies that efforts to shorten unemployment durations through job-finding bonuses or more stringent search requirements would yield welfare gains 60 percent smaller than suggested by prior studies that attributed the entire duration response to a substitution effect. 


\section{Conclusion}

This paper has proposed and implemented an "exact identification" approach to welfare analysis. In particular, I showed that the welfare gain from increasing the unemployment benefit level can be well approximated by estimating a pair of high-level elasticities rather than identifying the full set of primitives. The central intuition is that UI benefits affect search behavior through two channels: a welfareenhancing "liquidity effect" and a welfare-reducing moral hazard effect. The ratio of the liquidity effect to the moral hazard effect is a sufficient statistic for the welfare gain of raising the benefit level in a general environment. Using data from the United States, I estimate that the liquidity effect accounts for 60 percent of the marginal effect of UI benefits on durations at current benefit rates. This estimate implies that a benefit equal to 50 percent of the preunemployment wage is near optimal in a UI system that pays constant benefits for 6 months.

Although this paper has focused on unemployment, the theoretical concepts have broader applicability. Revealed preference can be used to calculate the welfare gains from social and private insurance policies by separating moral hazard and liquidity effects. For example, one can calculate the value of a health insurance program by estimating the extent to which an agent's medical expenditures would differ if he were paid a lump-sum benefit rather than an indemnity benefit that covers health expenses. This method does not require data on the outcomes of insurance provision, such as health, consumption, or job match quality, which have proved to be difficult to measure. ${ }^{35}$

More generally, developing exact identification strategies to analyze optimal policy in contexts beyond insurance should be a high priority for further work. Such strategies offer the promise of combining the best feature of reduced-form empirical analysis-transparent and credible identification - with the benefit of structural models- the ability to make precise statements about welfare.

\section{Appendix A}

\section{Proofs}

Derivation of the Decomposition in (9)

For any variable $x \in\{a, b, w\}$ and $s \leq T$, let

$$
\left.\frac{\partial y}{\partial x}\right|_{s}=\sum_{t=0}^{s} \frac{\partial y}{\partial x_{t}}
$$

${ }^{35}$ See Nyman (2003) and Autor and Duggan (2007) for evidence on moral hazard vs. liquidity effects in health and disability insurance. 
denote the effect of increasing $x$ in all periods 0 to $s$ on $y$. Then it follows that

$$
\left.\frac{\partial s_{0}}{\partial x}\right|_{s}=\frac{1}{\psi^{\prime \prime}\left(s_{0}\right)}\left(\left.\frac{\partial V_{0}}{\partial x}\right|_{s}-\left.\frac{\partial U_{0}}{\partial x}\right|_{s}\right)
$$

Note that $\left.\left(\partial s_{0} / \partial b\right)\right|_{B}=\partial s_{0} / \partial b$ because UI benefits and the annuity last for only $B$ periods by assumption. Exploiting the envelope conditions from agent optimization, we obtain the following derivatives for the value functions:

$$
\begin{aligned}
\frac{\partial U_{0}}{\partial b} & =u^{\prime}\left(c_{0}^{u}\right)+\sum_{t=1}^{B-1} \prod_{i=1}^{t}\left(1-s_{i}\right) u^{\prime}\left(c_{t}^{u}\right), \\
\frac{\partial V_{0}}{\partial b} & =0 \\
\left.\frac{\partial U_{0}}{\partial w}\right|_{B} & =s_{1}(B-1) v^{\prime}\left(c_{1}^{e}\right)+\sum_{t=2}^{B-1}\left[\prod_{i=2}^{t}\left(1-s_{i-1}\right)\right] s_{t}(B-t) v^{\prime}\left(c_{t}^{e}\right), \\
\left.\frac{\partial V_{0}}{\partial w}\right|_{B} & =B v^{\prime}\left(c_{0}^{e}\right), \\
\left.\frac{\partial U_{0}}{\partial a}\right|_{B} & =\frac{\partial U_{0}}{\partial b}+\left.\frac{\partial U_{0}}{\partial w}\right|_{B} \\
\left.\frac{\partial V_{0}}{\partial a}\right|_{B} & =\left.\frac{\partial V_{0}}{\partial w}\right|_{B}
\end{aligned}
$$

From these expressions and equation (A1), it follows that

$$
\frac{\partial s_{0}}{\partial b}=\left.\frac{\partial s_{0}}{\partial a}\right|_{B}-\left.\frac{\partial s_{0}}{\partial w}\right|_{B}
$$

\section{Proof of Proposition 1}

To begin, observe that the unconditional average marginal utility of consumption while employed over the first $B$ periods is

$$
\begin{aligned}
E_{0, B-1} v^{\prime}\left(c_{t}^{e}\right) & =\frac{1}{B-D_{B}}\left\{s_{0} B v^{\prime}\left(c_{0}^{e}\right)+\sum_{t=1}^{B-1}\left[\prod_{i=1}^{t}\left(1-s_{i-1}\right)\right] s_{t}(B-t) v^{\prime}\left(c_{t}^{e}\right)\right\} \\
& =\frac{1}{B-D_{B}}\left[\left.\left(1-s_{0}\right) \frac{\partial U_{0}}{\partial w}\right|_{B}+\left.s_{0} \frac{\partial V_{0}}{\partial w}\right|_{B}\right]
\end{aligned}
$$


The average marginal utility of consumption while employed conditional on finding a job in period 0 is

$$
E_{0, B-1} v^{\prime}\left(c_{0}^{e}\right)=v^{\prime}\left(c_{0}^{e}\right)=\left.\frac{1}{B} \frac{\partial V_{0}}{\partial w}\right|_{B} .
$$

To derive (14), recall that $J_{0}=\left(1-s_{0}\right) U_{0}(b, \tau)+s V_{0}(b, \tau)+\psi\left(s_{0}\right)$. Therefore,

$$
\begin{aligned}
\frac{d J_{0}}{d b} & =\left(1-s_{0}\right)\left(\frac{\partial U_{0}}{\partial b}-\frac{\partial U_{0}}{\partial w} \frac{d \tau}{d b}\right)-s_{0} \frac{\partial V_{0}}{\partial w} \frac{d \tau}{d b} \\
& =-\left(1-s_{0}\right) \psi^{\prime \prime} \frac{\partial s_{0}}{\partial b}-\frac{d \tau}{d b}(T-D) E_{0, T-1} v^{\prime}\left(c_{t}^{e}\right) .
\end{aligned}
$$

Next, I normalize the expression for $d J_{0} / d b$ by the expected welfare gain from increasing the wage by $\$ 1.00, d J_{0} / d w=(T-D) E_{0, T-1} v^{\prime}\left(c_{t}^{e}\right)$ :

$$
\frac{\partial W}{\partial b}=\frac{d J_{0}}{d b} \mid \frac{d J_{0}}{d w}=-\frac{1}{T-D} \frac{1-s_{0}}{E_{0, T-1} v^{\prime}\left(c_{t}^{e}\right)} \psi^{\prime \prime} \frac{\partial s_{0}}{\partial b}-\frac{d \tau}{d b} .
$$

Using (A1) and the definitions of $E_{0, B-1} v^{\prime}\left(c_{0}^{e}\right)$ and $E_{0, B-1} v^{\prime}\left(c_{t}^{e}\right)$, we obtain

$$
\left.\frac{\partial s_{0}}{\partial w}\right|_{B}=\frac{1}{\psi^{\prime \prime}} \frac{1}{1-s_{0}}\left[B v^{\prime}\left(c_{0}^{e}\right)-\left(B-D_{B}\right) E_{0, B-1} v^{\prime}\left(c_{t}^{e}\right)\right] .
$$

This expression implies that

$$
\left.\frac{\partial s_{0}}{\partial w}\right|_{B} \frac{\partial s_{0}}{\partial w}=\frac{D_{B} E_{0, B-1} v^{\prime}\left(c_{t}^{e}\right)+B\left[v^{\prime}\left(c_{0}^{e}\right)-E_{0, B-1} v^{\prime}\left(c_{t}^{e}\right)\right]}{D E_{0, T-1} v^{\prime}\left(c_{t}^{e}\right)+T\left[v^{\prime}\left(c_{0}^{e}\right)-E_{0, T-1} v^{\prime}\left(c_{t}^{e}\right)\right]} .
$$

When the preceding equations are combined, some algebra yields

$$
\frac{d W}{d b}=\frac{D_{B}}{T-D}\left[-\frac{E_{0, B-1} v^{\prime}\left(c_{t}^{e}\right)-v^{\prime}\left(c_{0}^{e}\right)}{E_{0, T-1} v^{\prime}\left(c_{t}^{e}\right)} \frac{B}{D_{B}}-\frac{E_{0, B-1} v^{\prime}\left(c_{t}^{e}\right)}{E_{0, T-1} v^{\prime}\left(c_{t}^{e}\right)}\right]\left[\frac{\partial s_{0} / \partial a}{\left.\left(\partial s_{0} / \partial w\right)\right|_{B}}-1\right]-\frac{d \tau}{d b} .
$$

Differentiating the government's budget constraint, we obtain

$$
\frac{d \tau}{d b}=\frac{D_{B}}{T-D}\left(1+\varepsilon_{D_{B}, b}+\varepsilon_{D, b} \frac{D}{T-D}\right)
$$

Plugging this expression into the formula for $d W / d b$ above and collecting terms yields (14). QED.

\section{Extension 1: Ex Ante Behavior}

The main steps of the proof are the same as in proposition 1. I first write $d W / d b$ in terms of marginal utilities as in (10) and then show how this representation can be linked to $\left[\left.\left(\partial s_{0} / \partial a\right)\right|_{B}\right] \mid A_{0}, z$ and $\left(\partial s_{0} / \partial b\right) \mid A_{0}$, z-effects of $a$ and $b$ on $s_{0}$ holding $A_{0}$ and $z$ fixed. Recall that

$$
\frac{d W}{d b} \equiv \frac{d J_{-1}}{d b} \mid \sum_{t=-1}^{T-1} \frac{d J_{-1}}{d w_{t}}
$$


Computing these derivatives explicitly gives

$$
\begin{aligned}
\frac{d J_{-1}}{d b}= & -v^{\prime}\left(c_{-1}^{e}\right) \frac{d \tau}{d b}-(1-p) T v^{\prime}\left(\frac{A_{0}-\omega(z)+\sum w_{t}}{T}-\tau\right) \frac{d \tau}{d b}+p \frac{d J_{0}}{d b} \\
= & -v^{\prime}\left(c_{-1}^{e}\right) \frac{d \tau}{d b}-(1-p) T v^{\prime}\left(\frac{A_{0}-\omega(z)+\sum w_{t}}{T}-\tau\right) \frac{d \tau}{d b} \\
& +p\left[\left(1-s_{0}\right)\left(\frac{\partial U_{0}}{\partial b}-\frac{\partial U_{0}}{\partial w} \frac{d \tau}{d b}\right)-s_{0} \frac{\partial V_{0}}{\partial w} \frac{d \tau}{d b}\right], \\
\sum_{t=-1}^{T-1} \frac{d J_{-1}}{d w_{t}}= & (T+1-p D) E_{0, T-1} v^{\prime}\left(c_{t}^{e}\right) .
\end{aligned}
$$

When the approximation that $v^{\prime}\left(c_{t}^{e}\right)=v^{\prime}\left(c_{0}^{e}\right)$ for all $t$ is used, these expressions simplify to

$$
\begin{aligned}
\frac{d J_{-1}}{d b} & =p\left(1-s_{0}\right) \frac{\partial U_{0}}{\partial b}-\frac{d \tau}{d b}(T+1-p D) v^{\prime}\left(c_{0}^{e}\right), \\
\sum_{t=-1}^{T-1} \frac{d J_{-1}}{d w_{t}} & =(T+1-p D) v^{\prime}\left(c_{0}^{e}\right) \\
\Rightarrow \frac{d W}{d b} & =\frac{p\left(1-s_{0}\right)}{T+1-p D} \frac{\partial U_{0}}{\partial b} / v^{\prime}\left(c_{0}^{e}\right)-\frac{d \tau}{d b} .
\end{aligned}
$$

This marginal-utility representation is analogous to equation (A1) in the proof of proposition 1. To rewrite this equation in terms of moral hazard and liquidity effects, consider the following comparative statics:

$$
\begin{gathered}
\frac{\partial s_{0}}{\partial b} \mid A_{0}, z=-\frac{1}{\psi^{\prime \prime}} \frac{\partial U_{0}}{\partial b}, \\
\left(\left.\frac{\partial s_{0}}{\partial a}\right|_{B}\right) \mid A_{0}, z=\frac{1}{\psi^{\prime \prime}}\left(\left.\frac{\partial V_{0}}{\partial a}\right|_{B}-\left.\frac{\partial U_{0}}{\partial a}\right|_{B}\right)=-\frac{1}{\psi^{\prime \prime}} \frac{\partial U_{0}}{\partial b}+\frac{1}{\psi^{\prime \prime}} \frac{1}{1-s_{0}} D_{B} v^{\prime}\left(c_{t}^{e}\right) .
\end{gathered}
$$

Combining these equations, one can easily see that

$$
1+\frac{-\frac{\partial s_{0}}{\partial a} \mid A_{0}, z}{\frac{\partial s_{0}}{\partial a}\left|A_{0}, z-\frac{\partial s_{0}}{\partial b}\right| A_{0}, z}=\left(1-s_{0}\right) \frac{\partial U_{0}}{\partial b} \mid v^{\prime}\left(c_{t}^{e}\right) .
$$

Differentiating the government's budget constraint and using the approximation $\varepsilon_{D, b}=\varepsilon_{D_{B}, b}$, we obtain

$$
\frac{d \tau}{d b}=\frac{p D_{B}}{T+1-p D}\left(1+\frac{T+1}{T+1-p D} \varepsilon_{D_{B}, b}\right) .
$$


Finally, plugging these expressions into the formula for $d W / d b$ above and collecting terms yields

$$
\frac{d W}{d b}=\frac{1-\sigma}{\sigma} \frac{D_{B}}{D}\left(R-\frac{\varepsilon_{D_{B}, b}}{\sigma}\right)
$$

where $\sigma=(T+1-p D) /(T+1)$ and

$$
R=\frac{-\left(\left.\frac{\partial s_{0}}{\partial a}\right|_{B}\right) A_{0}, z}{\left(\left.\frac{\partial s_{0}}{\partial a}\right|_{B}\right) A_{0}, z-\left.\frac{\partial s_{0}}{\partial b}\right|_{0}, z}
$$

is the liquidity to moral hazard ratio, with ex ante behaviors held fixed.

Extension 2: Stochastic Wage Offers

Suppose that with probability $s_{t}$ (controlled by search intensity) the agent is offered a wage $w \sim w_{m}+F(w)$. Assume no recall of previous offers and independent and identically distributed draws across periods. The agent follows a reservation wage policy: in each period $t$, there is a threshold $R_{t}$ such that the agent accepts a job only if the wage $w>R_{t}$ (McCall 1970). I generalize corollary 1 to this model in the following steps: (1) specify the value functions, (2) write the marginal welfare gain from raising $b$ in terms of expected marginal utilities, and (3) relate the gap in marginal utilities to the comparative statics of search intensity. For simplicity, assume $B=T$.

The value function for an individual with assets $A_{t}$ who finds and accepts a job at the beginning of period $t$ that pays a wage $w$ is

$$
V_{t}\left(w, A_{t}\right)=\max _{A_{t+1} \geq L} v\left(A_{t}-A_{t+1}+w\right)+V_{t+1}\left(w, A_{t+1}\right) .
$$

The value function for an individual who fails to find a job at the beginning of period $t$ and remains unemployed is

$$
U_{t}\left(A_{t}\right)=\max _{A_{t+1} \geq L} u\left(A_{t}-A_{t+1}+b_{t}\right)+J_{t+1}\left(A_{t+1}\right),
$$

where $J_{t+1}\left(A_{t+1}\right)$ is the value of entering period $t+1$ unemployed with assets $A$. The probability of finding and accepting a job in period $t$ is $s_{t} P\left(w \geq R_{t}\right)$, where $P\left(w \geq R_{t}\right)=\int_{R_{t}}^{\infty} d F(w)$. It follows that

$$
J_{t}\left(A_{t}\right)=\max _{s_{t} R_{t}} s_{t} P\left(w \geq R_{t}\right) E V_{t}+\left[1-s_{t} P\left(w \geq R_{t}\right)\right] U_{t}\left(A_{t}\right)-\psi\left(s_{t}\right),
$$

where

$$
E V_{t}=E\left[V_{t}\left(w, A_{t}\right) \mid w \geq R_{t}\right]=\frac{1}{P\left(w \geq R_{t}\right)} \int_{R_{t}}^{\infty}\left[V_{t}\left(w, A_{t}\right)\right] d w
$$

represents the expected value of being employed conditional on receiving an 
acceptable offer. Let $P=P\left(w \geq R_{0}\right)$ in what follows. The marginal welfare gain from raising the UI benefit is

$$
\frac{d J_{0}}{d b}=\left(1-P s_{0}\right) \frac{\partial U_{0}}{\partial b}-\frac{d \tau}{d b}\left[\left(1-P s_{0}\right) \frac{\partial U_{0}}{\partial w_{m}}+P s_{0} \frac{\partial E V_{0}}{\partial w_{m}}\right] .
$$

The marginal welfare gain of raising the wage by $\$ 1.00$ in all states and periods is

$$
\frac{d J_{0}}{d w_{m}}=\left(1-P s_{0}\right) \frac{\partial U_{0}}{\partial w_{m}}+P s_{0} \frac{\partial E V_{0}}{\partial w_{m}}=(T-D) E v^{\prime}\left(c_{t}^{e}\right),
$$

where $E v^{\prime}\left(c_{t}^{e}\right)$ denotes the average marginal utility of consumption while employed. The latter equality follows from differentiating the value functions and exploiting the envelope conditions for $s_{t}$ and $R_{t}$, as in the derivation of (9) above.

When these equations are combined, the money-metric measure for the welfare gain from raising $b$ is

$$
\frac{d W}{d b}=\frac{d J_{0}}{d b}\left|\frac{d J_{0}}{d w_{m}}=\left(1-P s_{0}\right) \frac{\partial U_{0}}{\partial b}\right|(T-D) E v^{\prime}\left(c_{t}^{e}\right)-\frac{d \tau}{d b} .
$$

To write this expression in terms of the liquidity and moral hazard effects on search intensity, note that the first-order condition for $s_{0}$ is

$$
P E V_{0}\left(A_{0}, a\right)-P U_{0}\left(A_{0}, a, b\right)=\psi^{\prime}\left(s_{0}\right),
$$

which is a simple generalization of (4), replacing the value function $V$ with its expected value and integrating over the wage distribution. Differentiating the first-order condition yields the following comparative statics:

$$
\begin{aligned}
& \frac{\partial s_{0}}{\partial b}=-P \frac{\partial U_{0}}{\partial b} / \psi^{\prime \prime}\left(s_{0}\right), \\
& \frac{\partial s_{0}}{\partial a}=P\left(\frac{\partial E V_{0}}{\partial a}-\frac{\partial U_{0}}{\partial a}\right) / \psi^{\prime \prime}\left(s_{0}\right), \\
& \frac{\partial s_{0}}{\partial w_{m}}=P\left(\frac{\partial E V_{0}}{\partial w_{m}}-\frac{\partial U_{0}}{\partial w_{m}}\right) / \psi^{\prime \prime}\left(s_{0}\right) .
\end{aligned}
$$

If the agent finds a job in period 0 , the average marginal utility of consumption (integrating over the wage distribution) is $\partial E V_{0} / \partial w_{m}=T E v^{\prime}\left(c_{0}^{e}\right)$. From (A3), it follows that

$$
\frac{\partial U_{0}}{\partial w_{m}}=\frac{(T-D) E v^{\prime}\left(c_{t}^{e}\right)-P s_{0} T v^{\prime}\left(c_{0}^{e}\right)}{1-P s_{0}} .
$$

Hence the effect of raising the wage in all states and periods by $\$ 1.00$ on search intensity is

$$
\frac{\partial s_{0}}{\partial w_{m}}=P\left[T E v^{\prime}\left(c_{0}^{e}\right)-\frac{(T-D) E v^{\prime}\left(c_{t}^{e}\right)-P s_{0} T v^{\prime}\left(c_{0}^{e}\right)}{1-P s_{0}}\right] / \psi^{\prime \prime}\left(s_{0}\right)
$$

To simplify this expression, make the approximation that the average marginal 
utility of consumption is constant over time, that is, $E v^{\prime}\left(c_{0}^{e}\right)=E v^{\prime}\left(c_{t}^{e}\right)$. This approximation implies

$$
\frac{\partial s_{0}}{\partial w_{m}}=\frac{P}{\psi^{\prime \prime}} \frac{D E v^{\prime}\left(c_{t}^{e}\right)}{1-P s_{0}} .
$$

Using the expressions for $\partial s_{0} / \partial b$ and $\partial s_{0} / \partial w_{m}$, we obtain

$$
\frac{d W}{d b}=-\frac{\left(1-P s_{0}\right)\left[\psi^{\prime \prime}\left(s_{0}\right) \partial s_{0} / \partial b\right] / P}{\left(1-P s_{0}\right)\left[\psi^{\prime \prime}\left(s_{0}\right) \partial s_{0} / \partial w_{m}\right] / P} \frac{D}{T-D}-\frac{d \tau}{d b} .
$$

Differentiating the government's budget constraint yields

$$
\frac{d \tau}{d b}=\frac{D}{T-D}\left(1+\varepsilon_{D, b} \frac{T}{T-D}\right)
$$

Plugging in this expression and collecting terms, we obtain

$$
\frac{d W}{d b}=\frac{1-\sigma}{\sigma}\left[-\frac{\partial s_{0} / \partial a}{\left(\partial s_{0} / \partial a\right)-\left(\partial s_{0} / \partial b\right)}-\frac{\varepsilon_{D_{B, b}}}{\sigma}\right]
$$

which is precisely the same formula as in corollary 1 .

The problem in implementing (A4) empirically is that the reemployment hazard in period $t$ is $h_{t}=s_{t}\left[1-F\left(R_{t}\right)\right]$. Therefore, changes in $h_{t}$ that are observed in the data cannot be directly mapped to changes in $s_{t}$. To address this problem, note that the expected accepted wage is

$$
\bar{w}_{t}=E\left[w_{t} \mid w_{t}>R_{t}\right]=\int_{R_{t}}^{\infty} \frac{w_{t} d F\left(w_{t}\right)}{1-F\left(R_{t}\right)} .
$$

Letting the density of the wage distribution be denoted by $f(w)$, we have

$$
\frac{\partial \bar{w}_{t}}{\partial R_{t}}=\left(\bar{w}_{t}-R_{t}\right) \frac{f\left(R_{t}\right)}{1-F\left(R_{t}\right)} .
$$

For any variable $x \in\{a, b\}$, the effect of a change in $x$ on the average accepted wage is

$$
\frac{\partial \bar{w}_{t}}{\partial x}=\left(\bar{w}_{t}-R_{t}\right) \frac{f\left(R_{t}\right)}{1-F\left(R_{t}\right)} \frac{\partial R_{t}}{\partial x} .
$$

The effect of a change in $x$ on the reemployment hazard in period $t$ is

$$
\frac{\partial \log h_{t}}{\partial x}=\frac{\partial \log s_{t}}{\partial x}-\frac{f\left(R_{t}\right)}{1-F\left(R_{t}\right)} \frac{\partial R_{t}}{\partial x} .
$$

Combining these equations yields

$$
\frac{\partial \log s_{t}}{\partial x}=\frac{\partial \bar{w}_{t}}{\partial x} \frac{1}{\bar{w}_{t}-R_{t}}+\frac{\partial \log h_{t}}{\partial x} .
$$


Finally, plugging this expression with $x=a$ and $x=b$ into (A4) gives

$$
\begin{aligned}
\frac{d W}{d b}= & \frac{1-\sigma}{\sigma}\left\{-\left(\frac{\partial \bar{w}_{0}}{\partial a} \bar{w}_{0}-R_{0}+\frac{\partial \log h_{0}}{\partial a}\right)\right. \\
& \left.\div\left[\left(\frac{\partial \bar{w}_{0}}{\partial a} \frac{1}{\bar{w}_{0}-R_{0}}+\frac{\partial \log h_{0}}{\partial a}\right)-\left(\frac{\partial \bar{w}_{0}}{\partial b} \frac{1}{\bar{w}_{0}-R_{0}}+\frac{\partial \log h_{0}}{\partial b}\right)\right]-\frac{\varepsilon_{D_{B},}}{\sigma}\right\} .
\end{aligned}
$$

This formula shows that one can calculate $d W / d b$ when wage offers are stochastic using information about the reservation wage $R_{0}$ and the effect of benefits and cash grants on mean accepted wages. If $\partial x_{t} / \partial A_{0}=0$ and $\partial x_{t} / \partial b=0$, (A7) collapses back to

$$
\frac{d W}{d b}=\frac{1-\sigma}{\sigma}\left[-\frac{\partial h_{0} / \partial a}{\left(\partial h_{0} / \partial a\right)-\left(\partial h_{0} / \partial b\right)}-\frac{\varepsilon_{D_{B}, b}}{\sigma}\right],
$$

which is exactly the formula implemented in Section V.

\section{Extension 3: Heterogeneity}

For simplicity, consider the baseline model with $T=1$. Suppose that the economy has $N$ individuals, indexed by $i$. Let $u_{i}, v_{i}$, and $\psi_{i}$ denote the consumption utility functions of agent $i$. Let $A_{0}^{i}$ denote initial assets and $w_{0}^{i}$ denote the wage. The government's objective is to maximize the sum of the agent's expected utilities subject to the constraint that total benefits paid equal totals taxes collected in expectation:

$$
\begin{aligned}
& \max _{b_{0}} \tilde{W}\left(b_{0}\right)=\sum_{i=1}^{N}\left\{\left[1-s_{0}^{i}\left(b_{0}\right)\right] u_{i}\left(A_{0}^{i}+b_{0}\right)+s_{0}^{i}\left(b_{0}\right) v_{i}\left(A_{0}^{i}+w_{0}^{i}-\tau\right)-\psi_{i}\left(s_{0}^{i}\left(b_{0}\right)\right)\right\} \\
& \text { subject to } b_{0} \sum_{i=1}^{N}\left[1-s_{0}^{i}\left(b_{0}\right)\right]=\tau \sum_{i=1}^{N} s_{0}^{i}\left(b_{0}\right) .
\end{aligned}
$$

Let $E s_{0}=\sum_{i=1}^{N} s_{0}^{i} / N$ denote mean search intensity in the population,

$$
E u^{\prime}\left(c_{0}^{u}\right)=\sum_{i=1}^{N}\left(1-s_{0}^{i}\right) u_{i}^{\prime}\left(c_{0, i}^{u}\right) / \sum_{i=1}^{N}\left(1-s_{0}^{i}\right)
$$

denote mean marginal utility for those who are unemployed, and

$$
E v^{\prime}\left(c_{0}^{e}\right)=\sum_{i=1}^{N} s_{0}^{i} v_{i}^{\prime}\left(c_{0, i}^{e}\right) / \sum_{i=1}^{N} s_{0}^{i}
$$

denote mean marginal utility for those who are employed. It is straightforward to establish that

$$
\begin{aligned}
\frac{d \tilde{W}}{d b_{0}} & =\sum_{i=1}^{N}\left(1-s_{0}^{i}\right) u_{i}^{\prime}\left(c_{0, i}^{u}\right)-\sum_{i=1}^{N} s_{0}^{i} v_{i}^{\prime}\left(c_{0, i}^{e}\right) \frac{d \tau}{d b_{0}} \\
& =N\left(1-E s_{0}\right) E u^{\prime}\left(c_{0}^{u}\right)-N E s_{0} E v^{\prime}\left(c_{0}^{e}\right) \frac{d \tau}{d b_{0}} .
\end{aligned}
$$


The marginal welfare gain of raising the wage rate by $\$ 1.00$ for all agents is $\sum_{i=1}^{N} s_{0}^{i} v_{i}^{\prime}\left(c_{0, i}^{e}\right)=E s_{0} E v^{\prime}\left(c_{0}^{e}\right)$. Note that

$$
\frac{d \tau}{d b_{0}}=\frac{1-E s_{0}}{E s_{0}}-\frac{1}{\left(E s_{0}\right)^{2}} b_{0} \frac{d E s_{0}}{d b_{0}} .
$$

Then it follows that

$$
\frac{d W}{d b_{0}}=\frac{d \tilde{W}}{d b_{0}} \mid E s_{0} E v^{\prime}\left(c_{0}^{e}\right)=N \frac{1-E s_{0}}{E s_{0}}\left[\frac{E u^{\prime}\left(c_{0}^{u}\right)-E v^{\prime}\left(c_{0}^{e}\right)}{E v^{\prime}\left(c_{0}^{e}\right)}-\frac{\varepsilon_{E 1-s, b_{0}}}{E s_{0}}\right],
$$

where

$$
\varepsilon_{E 1-s, b_{0}}=\frac{d\left(1-E s_{0}\right)}{d b_{0}} \frac{b_{0}}{1-E s_{0}}
$$

denotes the elasticity of the average fraction of time spent unemployed with respect to $b_{0}$. This equation is analogous to (10), showing that the per capita welfare gain from increasing $b_{0}$ can be expressed in terms of average marginal utilities when there is heterogeneity in the population.

To relate this expression to liquidity and moral hazard effects, observe that the ratio of the mean liquidity effect to the mean moral hazard effect is

$$
\bar{R}=\frac{E \partial s_{0}^{i} / \partial A_{0}^{i}}{E \partial s_{0}^{i} / \partial w_{0}^{i}}=E\left[\frac{v_{i}^{\prime}\left(c_{0, i}^{e}\right)-u_{i}^{\prime}\left(c_{0, i}^{u}\right)}{\psi_{i}^{\prime \prime}\left(s_{0}^{i}\right)}\right] / E\left[\frac{v_{i}^{\prime}\left(c_{0, i}^{e}\right)}{\psi_{i}^{\prime \prime}\left(s_{0}^{i}\right)}\right] .
$$

If the heterogeneity in the population is such that $v_{i}^{\prime}\left(c_{0, i}^{e}\right) \perp \psi^{\prime \prime}\left(s_{0}^{i}\right)$ and $u_{i}^{\prime}\left(c_{0, i}^{u}\right) \perp \psi^{\prime \prime}\left(s_{0}^{i}\right)$,

$$
\bar{R}=\frac{E u^{\prime}\left(c_{0}^{u}\right)-E v^{\prime}\left(c_{0}^{e}\right)}{E v^{\prime}\left(c_{0}^{e}\right)}
$$

and the per capita welfare gain is

$$
\frac{d W}{d b_{0}} \mid N=\frac{1-E s_{0}}{E s_{0}}\left(\bar{R}-\frac{\varepsilon_{E 1-s, b_{0}}}{E s_{0}}\right) .
$$

This expression coincides with (11), except that all the moments are replaced by population means. An analogous independence assumption and derivation following the proof of proposition 1 can be used to extend this result to $T>1$.

\section{Appendix B}

\section{SIPP Sample and Variable Definitions}

The data used in Section III are from the 1985, 1986, 1987, 1990, 1991, 1992 , 1993, and 1996 panels of the Survey of Income and Program Participation. The SIPP collected information from a sample of approximately 13,000 households in 1985 that grew over time to over 36,000 households in 1996. Interviews were conducted every 4 months for a period of 2-4 years, so the data span the beginning of 1985 to the middle of 2000 .

Pooling the eight panels yield a universe of 468,766 individuals from 149,286 households. Of these individuals, 99,880 experience at least one job separation (as defined below) during the sample period. Further restricting the sample to 
individuals between the ages of 18 and 65 who have at least 3 months of work history and have been included in the panel for at least 3 months leaves 78,168 individuals. Because of a problematic definition of unemployment status in the $1985-87$ versions of the SIPP, individuals sometimes report a job separation while also reporting unemployment duration equal to zero. Redefining unemployment status to include only those who report becoming unemployed and also a nonzero unemployment duration leaves 65,135 individuals.

I drop observations from Maine, Vermont, Iowa, North Dakota, South Dakota, Alaska, Idaho, Montana, and Wyoming because the SIPP does not provide unique state identifiers for individuals residing in these small states. This leaves me with a sample of 62,598 individuals and 86,921 unemployment spells. Of these spells, 33,149 are for women, whom I exclude. I also keep only those individuals who report actively searching for a job, as defined below, to eliminate those who have dropped out of the labor force. This leaves a sample of 16,784 individuals (3.6 percent of the original sample) who experienced a total of 21,796 unemployment spells. Next, I drop individuals who are temporarily laid off, since they may not have been actively searching for a new job, leaving 21,107 spells. I then exclude individuals who never received UI benefits, leaving 7,015 spells. Finally, I further limit the sample to individuals who take up benefits within the first month after job loss because it is unclear how UI should affect hazards for individuals who delay take-up. This last step produces a core sample consisting of 4,015 individuals ( 0.86 percent of the original sample) and 4,560 unemployment spells, of which 4,337 have asset and mortgage information.

Measurement of unemployment durations.-The measurement of unemployment durations in the SIPP differs from conventional measures because it requires the tabulation of responses to questions about employment at the weekly level. In particular, the SIPP reports the employment status of every individual over 15 years old for every week that they are in the sample. Weekly employment status (ES) can take the following values:

1. with a job this week-working

2. with a job, not on layoff, but absent without pay

3. with a job, but on layoff

4. no job-looking for work

5. no job-not looking for work

A job separation is defined as a change in ES from 1 or 2 to 3 , 4, or 5 . Following Cullen and Gruber (2000), I compute the duration of unemployment by summing the number of consecutive weeks that $\mathrm{ES} \geq 3$, starting at the date of job separation and stopping when the individual finds a job that lasts for at least 1 month (i.e., reports a string of four consecutive $\mathrm{ES}=1$ or $\mathrm{ES}=2$ ). Individuals are defined as being on temporary layoff if they report ES $=3$ at any point in the spell. They are defined as "searching" if they report ES $=4$ at any point during their spell.

Prediction of individual-level unemployment benefits.-I estimate a first-stage equation for earnings using OLS on the full sample of individuals who report a job loss at some point during the sample period. I regress nominal log wages in the year before job loss on years of education; age at job loss; years of tenure on the last job; a dummy for left-censoring of this job tenure variable; industry, occupation, month, and year dummies; and the unemployment rate in the relevant state/year. Since many individuals in the sample do not have a full year's earning's history before a job separation, I define the annual income of these individuals by assuming that they earned the average wage they report 
before they began participating in the SIPP. For example, individuals with one quarter of wage history are assumed to have an annual income of four times that quarter's income. Using the coefficient estimates, I predict log wages for each job loser and recover the predicted wage in levels. I then use this predicted wage to simulate the claimant's unemployment benefit using the UI benefit calculator under the assumption that wages are constant over the "base period" (typically the five quarters before job loss).

Note that simulating benefits using individuals' actual reported wage histories rather than the predicted wages yields a distribution of unemployment benefit levels that has much higher variance and a much weaker correlation with durations in the full sample. The predicted wage measure smooths the reported income fluctuations by isolating permanent differences in income correlated with stable characteristics such as education. Reassuringly, when the sample is restricted to observations in which the deviation between the predicted wage and actual reported wage is small (e.g., $<25$ percent), the point estimates for the specifications in table 2 obtained are similar to those obtained in the full sample.

\section{Appendix C}

\section{Mathematica Sample and Variable Definitions}

The data for the analysis in Section V come from two surveys conducted by Mathematica on behalf of the Department of Labor, matched with administrative data from state UI records. The data sets are publicly available through the Upjohn Institute. The first data set is the Pennsylvania Reemployment Bonus Demonstration, which contains information on 5,678 durations for a representative sample of job losers in Pennsylvania in 1991. This data set contains information on prior wages, weeks of UI paid, as well as demographic characteristics, household income, job characteristics (tenure, occupation, industry), and receipt of severance pay. The second data set is the Study of Unemployment Insurance Exhaustees, which contains data on the unemployment durations of 3,907 individuals who claimed UI benefits in 1998. This data set is a sample of unemployment durations in 25 states of the United States, with oversampling of individuals who exhausted UI benefits. The information in the data set is similar to that in the Pennsylvania study. Combining the two data sets yields a pooled sample containing 9,585 individuals. Note that Pennsylvania is not included in the exhaustees study, and hence there is only one year of data for each state in the sample.

For comparability, I make the same exclusions as in the SIPP. First, I include only prime-age males, dropping 44.7 percent of the original sample. Second, I exclude temporary layoffs by discarding all individuals who expected a recall at the time of layoff, dropping an additional 24.8 percent of the original sample. Finally, I drop all individuals with missing data on severance payments, years of job tenure, reported survey durations, or the variables used to predict net liquid wealth, losing another 5 percent of the original sample. These exclusions leave 2,441 individuals in the sample.

Consistent with the SIPP definition, I measure unemployment durations as the number of weeks elapsed from the end of the individual's prior job to the start of his next job as reported in the Mathematica survey.

Calculation of mean severance amounts.-Lee Hecht Harrison (2001) reports results from a survey of severance pay policies of human resource executives at 
925 corporations in the United States in 2001. At companies where the severance amount is based on years of service (which is the most common practice), the report provides a tabulation of the number of weeks of severance provided per week of service (see their table 1 in sec. II, p. 4). Using the percentages reported in this table for "nonexempts" (hourly workers) and coding the $<1$ week category as 0.5 week, I compute that, on average, individuals receive 1.35 weeks of severance pay per year of service. Lee Hecht Harrison reports that severance pay is typically capped at 26 weeks (6 months) for hourly workers. Defining the severance amount for each individual as $\min (1.35 \times$ job tenure, 26$)$, I compute that the average severance pay recipient in the Mathematica sample receives $7.77 \times 1.35=10.68$ weeks of wages in severance pay. The average severance pay amounts for the low-tenure and high-tenure groups discussed in Section IV are calculated using analogous methods.

\section{References}

$\rightarrow$ Acemoglu, Daron, and Robert Shimer. 1999. "Efficient Unemployment Insurance." J.P.E. 107 (October): 893-928.

$\rightarrow$ - 2000. "Productivity Gains from Unemployment Insurance." European Econ. Rev. 44 (June): 1195-1224.

$\rightarrow$ Anderson, Patricia, and Bruce Meyer. 1997. "Unemployment Insurance Takeup Rates and the After-Tax Value of Benefits." Q.J.E. 112 (August): 913-37.

$\rightarrow$ Autor, David, and Mark Duggan. 2007. "Income vs. Substitution Effects in Disability Insurance." A.E.R. Papers and Proc. 97 (May): 119-24.

$\rightarrow$ Baily, Martin N. 1978. "Some Aspects of Optimal Unemployment Insurance." J. Public Econ. 10 (December): 379-402.

$\rightarrow$ Bloemen, Hans, and Elena Stancanelli. 2005. "Financial Wealth, Consumption Smoothing and Income Shocks Arising from Job Loss." Economica 72 (August): 431-52.

Blundell, Richard, Luigi Pistaferri, and Ian Preston. 2008. "Consumption Inequality and Partial Insurance." A.E.R., forthcoming.

$\rightarrow$ Browning, Martin, and Thomas Crossley. 2001. "Unemployment Insurance Levels and Consumption Changes." J. Public Econ. 80 (April): 1-23.

$\rightarrow$ Card, David, Raj Chetty, and Andrea Weber. 2007. "Cash-on-Hand and Competing Models of Intertemporal Behavior: New Evidence from the Labor Market." Q.J.E. 122 (4): 1511-60.

$\rightarrow$ Carroll, Christopher. 1997. "Buffer-Stock Saving and the Life Cycle/Permanent Income Hypothesis.” Q.J.E. 112 (1): 1-56.

Chetty, Raj. 2003. "Consumption Commitments, Unemployment Durations, and Local Risk Aversion.” Working Paper no. 10211, NBER, Cambridge, MA

—. 2005. "Why Do Unemployment Benefits Extend Unemployment Durations? Moral Hazard vs. Liquidity.” Working Paper no. 11760 (November), NBER, Cambridge, MA.

$\rightarrow-$. 2006a. "A General Formula for the Optimal Level of Social Insurance." J. Public Econ. 90 (November): 1879-1901.

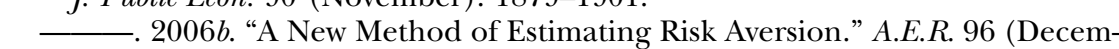
ber): $1821-34$.

- 2008. "Moral Hazard vs. Liquidity and Optimal Unemployment Insurance.” Working Paper no. 13967 (March), NBER, Cambridge, MA.

Chetty, Raj, and Emmanuel Saez. 2008. "Optimal Taxation and Social Insurance with Private Insurance Markets.” Manuscript, Univ. California, Berkeley. 
$\rightarrow$ Chetty, Raj, and Adam Szeidl. 2007. "Consumption Commitments and Risk Preferences.” Q.J.E. 122 (May): 831-77.

$\rightarrow$ Cochrane, John. 1991. "A Simple Test of Consumption Insurance." J.P.E. 99 (October): 957-76.

$\rightarrow$ Cullen, Julie, and Jonathan Gruber. 2000. "Does Unemployment Insurance Crowd Out Spousal Labor Supply?” J. Labor Econ. 18 (July): 546-72.

$\rightarrow$ Feldstein, Martin. 1978. "The Effect of Unemployment Insurance on Temporary Layoffs.” A.E.R. 68 (December): 834-46.

Feldstein, Martin, and Daniel Altman. 1998. "Unemployment Insurance Savings Accounts.” Working Paper no. 6860 (December), NBER, Cambridge, MA.

$\rightarrow$ Feldstein, Martin, and James Poterba. 1984. "Unemployment Insurance and Reservation Wages." J. Public Econ. 23 (February-March): 141-67.

$\rightarrow$ Gruber, Jonathan. 1997. "The Consumption Smoothing Benefits of Unemployment Insurance." A.E.R. 87 (March): 192-205.

- 1998. "Unemployment Insurance, Consumption Smoothing, and Private Insurance: Evidence from the PSID and CEX." In Research in Employment Policy, vol. 1, edited by Laurie J. Bassi and Stephen A. Woodbury. Stamford, CT: JAI. . 2007. Public Finance and Public Policy. 2nd ed. New York: Worth.

$\rightarrow$ Hansen, Gary, and Ayse Imrohoroglu. 1992. "The Role of Unemployment Insurance in an Economy with Liquidity Constraints and Moral Hazard.” J.P.E. 100 (February): 118-42.

$\rightarrow$ Hopenhayn, Hugo, and Juan Pablo Nicolini. 1997. "Optimal Unemployment Insurance." J.P.E. 105 (April): 412-38.

$\rightarrow$ Hurst, Erik, and Frank Stafford. 2004. "Home Is Where the Equity Is: Mortgage Refinancing and Household Consumption." J. Money, Credit, and Banking 36 (December): 985-1014.

$\rightarrow$ Johnson, David, Jonathan A. Parker, and Nicholas S. Souleles. 2006. "Household Expenditure and the Income Tax Rebates of 2001.” A.E.R. 96 (December): 1589-1610.

Kodrzycki, Yolanda. 1998. "The Effects of Employer-Provided Severance Benefits on Reemployment Outcomes." New England Econ. Rev. (November), pp. 4168.

Krueger, Alan, and Bruce Meyer. 2002. "Labor Supply Effects of Social Insurance." In Handbook of Public Economics, vol. 4, edited by Alan Auerbach and Martin Feldstein. Amsterdam: North-Holland.

Lee Hecht Harrison. 2001. Severance and Separation Benefits: Bridges for Employees in Transition. Woodcliff Lake, NJ: Lee Hecht Harrison.

Lentz, Rasmus. 2008. "Optimal Unemployment Insurance in an Estimated Job Search Model with Savings." Rev. Econ. Dynamics, forthcoming.

$\rightarrow$ Lentz, Rasmus, and Torben Tranaes. 2005. "Job Search and Savings: Wealth Effects and Duration Dependence.” J. Labor Econ. 23 (July): 467-89.

Lucas, Robert E., Jr. 1987. Models of Business Cycles. New York: Blackwell.

$\rightarrow$ McCall, John J. 1970. "Economics of Information and Job Search." Q.J.E. 84 (February): 113-26.

McCulloch, Kenneth. 1998. Termination of Employment: Employer and Employee Rights. Boston: Warren, Gorham and Lamont.

$\rightarrow$ Meyer, Bruce. 1990. "Unemployment Insurance and Unemployment Spells." Econometrica 58 (July): 757-82.

$\rightarrow$ Moffitt, Robert. 1985. "Unemployment Insurance and the Distribution of Unemployment Spells." J. Econometrics 28 (April): 85-101.

Nyman, John. 2003. The Theory of Demand for Health Insurance. Stanford, CA: Stanford Univ. Press. 
Pennsylvania Department of Labor and Industry. 2007. "Unemployment Compensation Regulations." http://www.dli.state.pa.us/landi/cwp/view.asp?a = $185 \& q=170005$.

Shimer, Robert, and Ivan Werning. 2006. "Liquidity and Insurance for the Unemployed." Staff Report no. 366 (December), Fed. Reserve Bank Minneapolis.

$\rightarrow \longrightarrow$. 2007. "Reservation Wages and Unemployment Insurance." Q.J.E. 122 (3): 1145-85.

Sullivan, James. Forthcoming. "Borrowing during Unemployment: Unsecured Debt as a Safety Net." J. Human Resources.

$\rightarrow$ Topel, Robert. 1983. "On Layoffs and Unemployment Insurance." A.E.R. 73 (September): 541-49.

$\rightarrow$ van Ours, Jan C., and Milan Vodopivec. 2008. "Does Reducing Unemployment Insurance Generosity Reduce Job Match Quality?” J. Public Econ. 92 (April): 684-95.

$\rightarrow$ Wolpin, Kenneth I. 1987. "Estimating a Structural Search Model: The Transition from School to Work." Econometrica 55 (4): 801-17.

$\rightarrow$ Zeldes, Stephen P. 1989. "Consumption and Liquidity Constraints: An Empirical Investigation.” J.P.E. 97 (April): 305-46. 